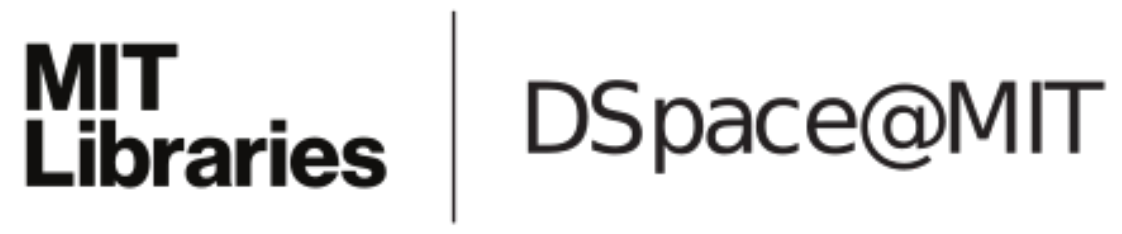

\author{
MIT Open Access Articles
}

\section{The Relationship between ITCZ Location and Cross- Equatorial Atmospheric Heat Transport: From the Seasonal Cycle to the Last Glacial Maximum}

The MIT Faculty has made this article openly available. Please share how this access benefits you. Your story matters.

Citation: Donohoe, Aaron, John Marshall, David Ferreira, and David Mcgee. “The Relationship Between ITCZ Location and Cross-Equatorial Atmospheric Heat Transport: From the Seasonal Cycle to the Last Glacial Maximum." J. Climate 26, no. 11 (June 2013): 3597-3618. (c) 2013 American Meteorological Society

As Published: http://dx.doi.org/10.1175/JCLI-D-12-00467.1

Publisher: American Meteorological Society

Persistent URL: http://hdl.handle.net/1721.1/85073

Version: Final published version: final published article, as it appeared in a journal, conference proceedings, or other formally published context

Terms of Use: Article is made available in accordance with the publisher's policy and may be subject to US copyright law. Please refer to the publisher's site for terms of use. 


\title{
The Relationship between ITCZ Location and Cross-Equatorial Atmospheric Heat Transport: From the Seasonal Cycle to the Last Glacial Maximum
}

\author{
Aaron Donohoe, John Marshall, David Ferreira, And David McGeE \\ Department of Earth and Planetary Sciences, Massachusetts Institute of Technology, Cambridge, Massachusetts
}

(Manuscript received 20 July 2012, in final form 26 October 2012)

\begin{abstract}
The authors quantify the relationship between the location of the intertropical convergence zone (ITCZ) and the atmospheric heat transport across the equator $\left(\mathrm{AHT}_{\mathrm{EQ}}\right)$ in climate models and in observations. The observed zonal mean ITCZ location varies from $5.3^{\circ} \mathrm{S}$ in the boreal winter to $7.2^{\circ} \mathrm{N}$ in the boreal summer with an annual mean position of $1.65^{\circ} \mathrm{N}$ while the $\mathrm{AHT}_{\mathrm{EQ}}$ varies from $2.1 \mathrm{PW}$ northward in the boreal winter to 2.3 PW southward in the boreal summer with an annual mean of $0.1 \mathrm{PW}$ southward. Seasonal variations in the ITCZ location and $\mathrm{AHT}_{\mathrm{EO}}$ are highly anticorrelated in the observations and in a suite of state-of-the-art coupled climate models with regression coefficients of $-2.7^{\circ}$ and $-2.4^{\circ} \mathrm{PW}^{-1}$ respectively. It is also found that seasonal variations in ITCZ location and $\mathrm{AHT}_{\mathrm{EQ}}$ are well correlated in a suite of slab ocean aquaplanet simulations with varying ocean mixed layer depths. However, the regression coefficient between ITCZ location and $\mathrm{AHT}_{\mathrm{EQ}}$ decreases with decreasing mixed layer depth as a consequence of the asymmetry that develops between the winter and summer Hadley cells as the ITCZ moves farther off the equator.

The authors go on to analyze the annual mean change in ITCZ location and $\mathrm{AHT}_{\mathrm{EO}}$ in an ensemble of climate perturbation experiments including the response to $\mathrm{CO}_{2}$ doubling, simulations of the Last Glacial Maximum, and simulations of the mid-Holocene. The shift in the annual average ITCZ location is also strongly anticorrelated with the change in annual mean $\mathrm{AHT}_{\mathrm{EQ}}$ with a regression coefficient of $-3.2^{\circ} \mathrm{PW}^{-1}$, similar to that found over the seasonal cycle.
\end{abstract}

\section{Introduction}

The atmospheric meridional overturning circulation in the tropics (the Hadley cell; Hadley 1735) controls the spatial distribution of both the tropical precipitation and the meridional heat transport in the atmosphere (AHT); the tropical precipitation maximum-the intertropical convergence zone (ITCZ) - is collocated with the ascending branch of the Hadley cell. The associated meridional AHT is in the direction of motion in the upper branch of the Hadley cell (Held 2001) and therefore is away from the location of ascending motion (see Fig. 1 for a schematic). Provided that the strength of the mass overturning circulation in the Hadley cell increases with meridional distance from the location of ascent, the magnitude of the atmospheric heat transport across

Corresponding author address: Aaron Donohoe, Massachusetts Institute of Technology, Department of Earth, Atmospheric and Planetary Sciences, Room 54-918, 77 Massachusetts Avenue, Cambridge, MA 02139-4307.

E-mail: thedhoe@mit.edu the equator $\left(\mathrm{AHT}_{\mathrm{EQ}}\right)$ is proportional to the location of the ITCZ relative to the equator, with a northern location corresponding to southward atmospheric heat transport across the equator (see Fig. 1). As a consequence, meridional shifts in the ITCZ location are expected to be accompanied by changes in $\mathrm{AHT}_{\mathrm{EQ}}$ across a myriad of time scales and climate states such as 1) the seasonal cycle, 2) paleoclimate states, 3) idealized climate simulations (Kang et al. 2008), and 4) changes due to increasing greenhouse gas concentrations (Frierson and Hwang 2012). The value of $\mathrm{AHT}_{\mathrm{EO}}$, in turn, is a consequence of the hemispheric difference in energy input to the atmosphere and is influenced by radiation, clouds, aerosols, ocean heat transport, and surface processes at all latitudes (Yoshimori and Broccoli 2008). As a result, forcing and feedbacks in the extratropics can remotely influence the location of the ITCZ (Chiang and Bitz 2005) by way of the mutual connection among the Hadley circulation, $\mathrm{AHT}_{\mathrm{EQ}}$, and the ITCZ location.

The relationship between AHT and the ITCZ location was recently demonstrated by Kang et al. (2008) in 


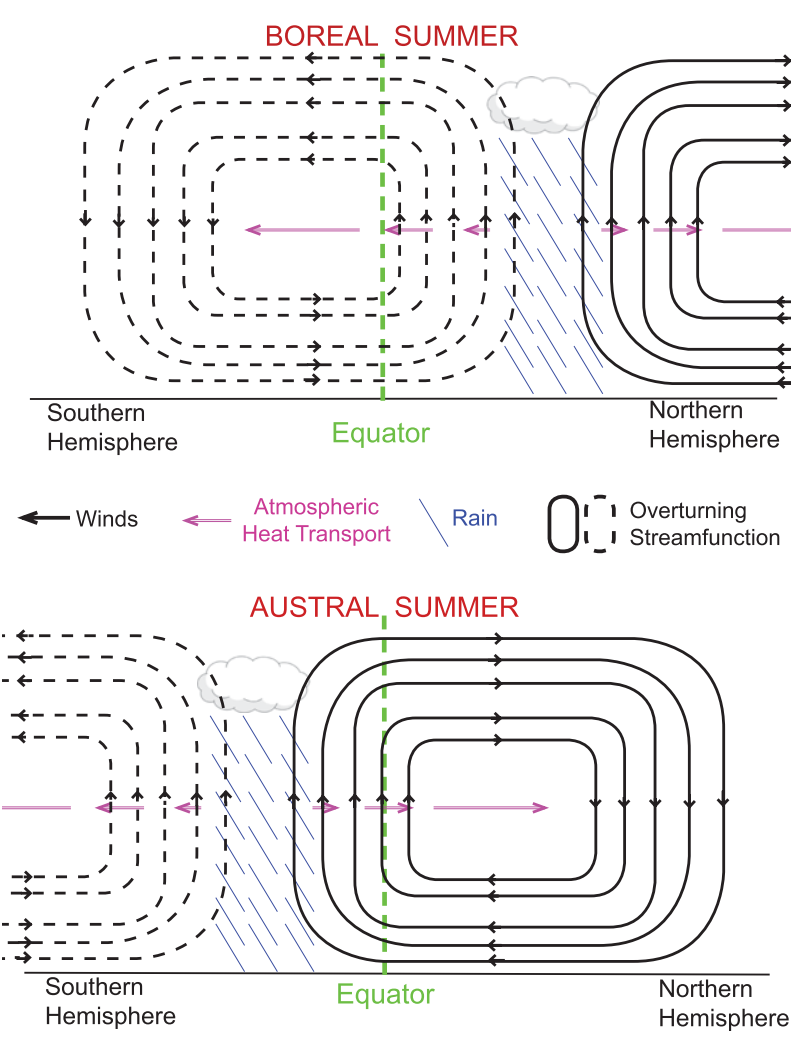

FIG. 1. Representation of the spatial structure of winds (gray arrows), meridional mass overturning streamfunction (solid and dashed gray contours for the positive and negative streamfunction values, respectively), precipitation (blue lines), and vertically integrated atmospheric heat transport (purple arrows) associated with the Hadley cell for (top) boreal summer and (bottom) austral summer. The equator is the dashed green line.

a slab ocean aquaplanet simulation where a hemispheric asymmetry in atmospheric heating was imposed by introducing a surface heating in the southern extratropics and an equal surface cooling in the northern extratropics. The ITCZ was found to shift toward the heat source and the precipitation maximum was nearly collocated with the location of zero meridional heat transport in the atmosphere, suggesting that a meridional shift of the Hadley cell was the underlying cause of the precipitation shift. Yoshimori and Broccoli $(2009,2008)$ found that the change in $\mathrm{AHT}_{\mathrm{EQ}}$ in response to hemispheric asymmetric forcing was closely related to the meridional shift in the Hadley cell, which itself was a response to the hemispheric asymmetry of the forcing and feedbacks. They also noted the concurrent shift in the tropical precipitation along with the Hadley cell but did not quantify the relationship between the change in $\mathrm{AHT}_{\mathrm{EQ}}$ and the meridional shift of the ITCZ. More recently, Frierson and Hwang (2012) found that the meridional shift in the ITCZ due to increased greenhouse gas concentrations in an ensemble of simulations was strongly correlated with the change in $\mathrm{AHT}_{\mathrm{EQ}}$. They also found that $\mathrm{AHT}_{\mathrm{EQ}}$ had a large intermodel spread due to differences in extratropical cloud responses. This suggests that the extratropics play an important role in setting the ITCZ location via the interhemispheric asymmetry in energy input to the atmosphere and the associated changes in $\mathrm{AHT}_{\mathrm{EQ}}$.

There is widespread paleoclimatic evidence for shifts and/or intensity changes of tropical precipitation in the past including a southward shift of the ITCZ during glacial times (Pahnke et al. 2007), abrupt transitions during glacial times (Wang et al. 2001; Peterson et al. 2000) associated with Dansgaard-Oeshchger and Heinrich events, a more northern location during the Holocene thermal maximum (Haug et al. 2001), and a southward shift (estimated to be approximately $5^{\circ}$ ) during the Little Ice Age (Sachs et al. 2009). Provided the same relationship between the ITCZ and $\mathrm{AHT}_{\mathrm{EQ}}$ holds across different climate states, each of the ITCZ shifts noted in the paleoclimate records would have an $\mathrm{AHT}_{\mathrm{EQ}}$ change that can be quantified. Moreover, the change in $\mathrm{AHT}_{\mathrm{EQ}}$ would have to be associated with a hemispheric asymmetry of atmospheric forcing or climate feedbacks (see Fig. 2). Thus, the quantitative relationship between ITCZ location and $\mathrm{AHT}_{\mathrm{EQ}}$ provides a framework for comparing precipitation shifts deduced from paleoclimate data and the proposed mechanisms and/or climate forcing that are believed to have caused the precipitation changes (i.e., orbital forcing, changes in land ice and sea ice, cloud albedo changes, a shutdown of the Atlantic meridional overturning circulation, etc.). There is also widespread paleoclimatic evidence for changes in meridional gradients of tropical sea surface temperature (SST) to which the ITCZ is sensitive. Furthermore, SST gradients may be easier to reconstruct from paleoproxies than ITCZ location. Therefore, a quantification of the relationship between SST gradients and ITCZ location is an important task for paleoclimate interpretation.

In this paper, we attempt to quantify the relationship between the location of the ITCZ and $\mathrm{AHT}_{\mathrm{EQ}}$ in models and observations. We demonstrate that this relationship is robust whether considering the seasonal migration of the ITCZ, the ITCZ shift due to anthropogenic forcing, or the ITCZ shift in past climates including the Last Glacial Maximum. We also study the relationship between tropical SST gradients and the ITCZ location. Our paper is organized as follows. In section 2 we analyze the seasonal cycle of the ITCZ location, $\mathrm{AHT}_{\mathrm{EQ}}$, and tropical SST gradients in both the observations (section 2a) and coupled climate models (section 2b). We also analyze the seasonal cycle in an ensemble of slab ocean aquaplanet simulations with ocean varying mixed layer depth (section 2c). In section 3, we focus on the 
Global Average

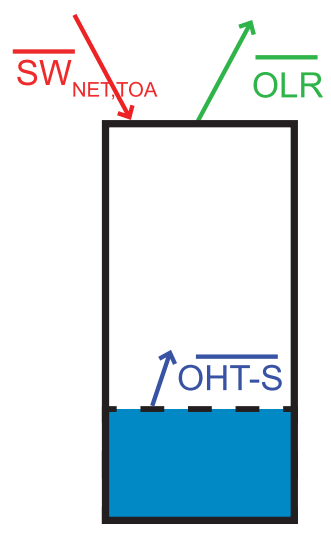

$\overline{S W}_{\mathrm{NET}, \mathrm{TOA}}=\overline{\mathrm{OLR}}$
Hemispheric Contrast

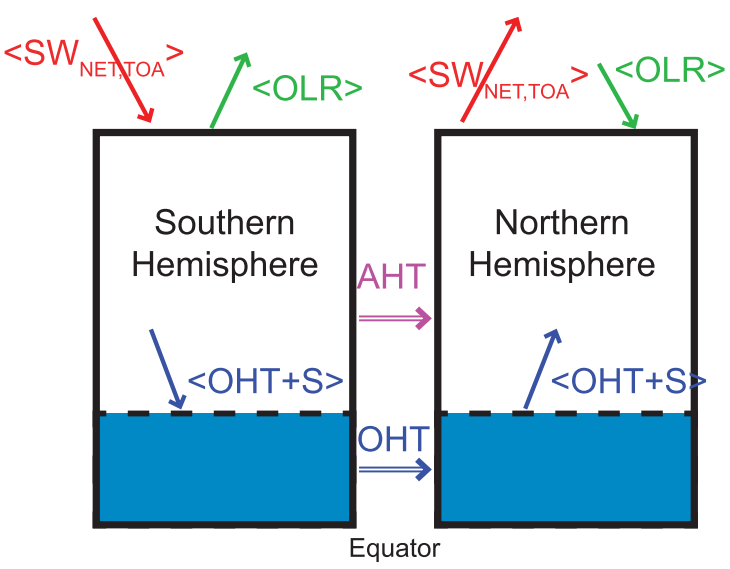

$\left.\left.\mathrm{AHT}_{\mathrm{EQ}}=\left\langle\mathrm{SW}_{\mathrm{NET}, \mathrm{TOA}}\right\rangle-<\mathrm{OLR}\right\rangle-<\mathrm{OHT}+\mathrm{S}\right\rangle$

Ocean Heat Transport and Storage

$$
\overline{\mathrm{OHT}}+\mathrm{S}=0
$$

FIG. 2. (left) The global, annual-averaged atmospheric energy budget and (middle), (right) the interhemispheric contrast of the energy budget used to derive the cross-equatorial atmospheric heat transport. The angle brackets indicate the SH integral minus the NH integral divided by 2 and $\mathrm{OHT}+S$ is the cross-equatorial ocean heat transport minus storage in each hemisphere.

annual mean shift in the ITCZ, $\mathrm{AHT}_{\mathrm{EQ}}$, and tropical SST gradients in model simulations of $\mathrm{CO}_{2}$ doubling, the Last Glacial Maximum, and 6000 years before present. We conclude with a summary and discussion in section 4 .

\section{Seasonal cycle of atmospheric heat transport and tropical precipitation}

In this section, we analyze the relationship between ITCZ location and $\mathrm{AHT}_{\mathrm{EQ}}$ over the seasonal cycle. In the boreal summer, the Northern Hemisphere $(\mathrm{NH})$ receives excess insolation relative to the annual mean, leading to atmospheric heating (Donohoe and Battisti 2013). In contrast, the Southern Hemisphere (SH) receives a deficit of insolation relative to the annual mean, leading to atmospheric cooling. The hemispheric asymmetry of atmospheric energy input is largely balanced by atmospheric energy transport from the source of atmospheric heating to the cooling, resulting in southward atmospheric heat transport across the equator (Fasullo and Trenberth 2008). The Hadley cell and ITCZ shift northward toward the warmer SSTs, which positions the southern branch of the Hadley cell over the equator, resulting in southward $\mathrm{AHT}_{\mathrm{EQ}}$ in the thermally direct Hadley cell. Similarly, in the austral summer, $\mathrm{AHT}_{\mathrm{EQ}}$ is northward and the ITCZ is in the Southern Hemisphere. We analyze the seasonal cycle of the observations in section $2 \mathrm{a}$, coupled models in section $2 \mathrm{~b}$, and slab ocean aquaplanet simulations with varying mixed layer depths in section 2c.

\section{a. Observations}

\section{1) DATA SOURCES AND METHODS}

Here we describe the data sources and calculation methods for analyzing the relationship among the ITCZ location, the tropical SST gradient, and $\mathrm{AHT}_{\mathrm{EQ}}$ in the observations.

\section{(i) Tropical precipitation and ITCZ location}

We use the precipitation climatology from the National Oceanographic and Atmospheric Administration (NOAA) Climate Prediction Center (CPC) merged analysis (Xie and Arkin 1996), a gridded data product that combines gauge measurements, satellite observations, and numerical models. The climatology is composed of data from 1981 to 2010. We use the precipitation centroid $\left(P_{\mathrm{CENT}}\right)$ defined by Frierson and Hwang $(2012)$ as a metric for the location of the ITCZ-tropical precipitation maximum. There, the precipitation centroid was defined as the median of the zonal average precipitation from $20^{\circ} \mathrm{S}$ to $20^{\circ} \mathrm{N}$. The precipitation is interpolated to a $0.1^{\circ}$ grid over 
the tropics to allow the precipitation centroid to vary at increments smaller than the grid spacing.

\section{(ii) Tropical SST gradient}

We use the Extended Reconstructed Sea Surface Temperature (ERSST) data from Reynolds and Smith (1994), version 3b (Smith et al. 2008), which takes ship and buoy measurements and produces a gridded dataset at $2^{\circ}$ resolution using an optimum interpolation method. We use the climatological data calculated between 1981 and 2010. As a metric for the interhemispheric difference of tropical SST, we calculate $\Delta \mathrm{SST}$ as the spatially weighted SST between the equator and $20^{\circ} \mathrm{N}$ minus the spatially weighted SST between the equator and $20^{\circ} \mathrm{S}^{1}$

\section{(iii) Atmospheric heat transport across the equator}

The atmospheric heat transport is derived from the National Centers for Environmental Prediction (NCEP) four-times-daily reanalysis fields (Kalnay et al. 1996) with a (horizontal) spectral resolution of T62 and 17 vertical levels. The atmospheric heat transport is calculated by first balancing the atmospheric mass budget in the reanalysis data with a barotropic wind correction as in Trenberth (1997) and subsequently calculating the meridional flux of moist static energy ${ }^{2}$ and vertically integrating. This procedure is used to compose monthly averaged atmospheric heat transport from 1981 to 2010 and the climatological average over this period is used in this study.

We now derive an expression for $\mathrm{AHT}_{\mathrm{EQ}}$ in terms of the hemispheric contrast of net energy (radiative and turbulent) input into the atmosphere (see Fig. 2) starting from the energy budget of the climate system at each latitude:

$$
\begin{aligned}
\mathrm{SW}_{\mathrm{NET}, \mathrm{TOA}}-\mathrm{OLR}= & \frac{d}{d t}\left[\frac{1}{g} \int_{0}^{P_{S}}\left(c_{p} T+L q\right) d P\right] \\
& +\nabla \cdot(\mathrm{OHT}+\mathrm{AHT})+\mathrm{OHS}
\end{aligned}
$$

where $\mathrm{SW}_{\text {NET,TOA }}$ is the net downwelling shortwave flux at the top of the atmosphere (TOA), OLR is the outgoing longwave radiation at the TOA, $T$ is temperature, $c_{p}$ is the heat capacity at constant pressure, $L$ is the latent heat of vaporization of water, $q$ is the specific humidity, $P_{S}$ is the surface pressure, and OHS is the

\footnotetext{
${ }^{1}$ Similar results are found using the regions equatorward of $15^{\circ}$ and $30^{\circ}$ in each hemisphere.

${ }^{2}$ Moist static energy is the sum of sensible, latent, and potential energy $\left(c_{p} T+L q+g Z\right)$.
}

ocean heat storage. And, $\boldsymbol{\nabla} \cdot(\mathrm{OHT}+\mathrm{AHT})$ is the divergence of the ocean and atmospheric heat transport, respectively. The global average (denoted by overbars) atmospheric energy budget for each month satisfies the equation

$$
\overline{\mathrm{SW}_{\mathrm{NET}, \mathrm{TOA}}}-\overline{\mathrm{OLR}}=\frac{d}{d t}\left[\frac{1}{g} \overline{\int_{0}^{P_{S}}\left(c_{p} T+L q\right) d P}\right]+\overline{\mathrm{OHS}}
$$

where the ocean and atmospheric energy flux divergences disappear in the global average. The left-hand side of the equation represents the net radiative heating of the climate system and the right-hand side represents energy storage in the atmosphere (we will hereafter denote this term as $\mathrm{STOR}_{\mathrm{atmos}}$ ) and ocean respectively. If we subtract Eq. (2) from Eq. (1) and spatially integrate over each hemisphere separately, we can derive an expression for $\mathrm{AHT}_{\mathrm{EQ}}$ by noting that the heat transport divergence averaged over the Southern Hemisphere equals the heat transport across the equator:

$$
\begin{aligned}
\mathrm{AHT}_{\mathrm{EQ}}= & \left\langle\mathrm{SW}_{\mathrm{NET}, \mathrm{TOA}}\right\rangle-\langle\mathrm{OLR}\rangle-\langle\mathrm{OHT}+S\rangle \\
& -\left\langle\mathrm{STOR}_{\text {atmos }}\right\rangle,
\end{aligned}
$$

where brackets indicate the spatial integral of the anomaly from the global averaged over the Southern Hemisphere (or, equivalently, the negative of the spatial integral over the Northern Hemisphere) and $\langle\mathrm{OHT}+S\rangle$ is the combined effect of cross-equatorial ocean heat transport and ocean heat storage in each hemisphere $(\langle\mathrm{OHT}+S\rangle$ is positive for northward oceanic heat transport at the equator and/or more heat storage in the Southern Hemisphere). A schematic of the interhemispheric energy budget cast in these terms is shown in Fig. 2. In the annual average, both $\left\langle\mathrm{STOR}_{\mathrm{atmos}}\right\rangle$ and ocean heat storage are zero if the system is in equilibrium and Eq. (4) simplifies to

$$
\mathrm{AHT}_{\mathrm{EQ}}=\left\langle\mathrm{SW}_{\mathrm{NET}, \mathrm{TOA}}\right\rangle-\langle\mathrm{OLR}\rangle-\mathrm{OHT}_{\mathrm{EQ}} .
$$

As discussed in Fasullo and Trenberth (2008), the predominant seasonal energy balance is between $\mathrm{SW}_{\mathrm{NET}, \mathrm{TOA}}$ and ocean heat storage and this near balance leads to compensating energy fluxes at the TOA and surface. We therefore follow the methodology of Donohoe and Battisti (2013) and divide the atmospheric heating into a component due to shortwave absorption in the atmospheric column (SWABS) and the upward flux of turbulent and longwave radiation from the surface to the atmosphere (SHF). Equation (4) becomes 
$\mathrm{AHT}_{\mathrm{EQ}}=\langle\mathrm{SWABS}\rangle-\langle\mathrm{OLR}\rangle+\langle\mathrm{SHF}\rangle-\left\langle\mathrm{STOR}_{\mathrm{atmos}}\right\rangle$,

where SWABS is the shortwave radiation absorbed in the atmosphere,

$$
\begin{aligned}
\mathrm{SWABS}= & \mathrm{SW} \downarrow_{\mathrm{TOA}}-\mathrm{SW} \uparrow_{\mathrm{TOA}}+\mathrm{SW} \uparrow_{\mathrm{SURF}} \\
& -\mathrm{SW} \downarrow_{\mathrm{SURF}},
\end{aligned}
$$

and represents the sun directly heating the atmosphere. Here SHF is energy fluxed from the surface to the atmosphere and is the sum of sensible heat fluxes (SENS), latent heat fluxes (LH), and longwave fluxes (LW) from the surface into the atmosphere:

$$
\begin{aligned}
\mathrm{SHF}= & \mathrm{SENS} \uparrow_{\mathrm{SURF}}+\mathrm{LH} \uparrow_{\mathrm{SURF}}+\mathrm{LW} \uparrow_{\mathrm{SURF}} \\
& -\mathrm{LW} \downarrow_{\mathrm{SURF}} .
\end{aligned}
$$

We note that Eq. (5) is merely a regrouping of the shortwave flux terms in Eq. (4). ${ }^{3}$

We use longwave and shortwave radiative fluxes from the Clouds and Earth's Radiant Energy System (CERES) experiment (Wielicki et al. 1996) to calculate $\langle$ SWABS $\rangle$ and $\langle\mathrm{OLR}\rangle$. All calculations are performed separately for each of the four CERES instruments (FM1 and FM2 on Terra from 2000 to 2005 and FM3 and FM4 on Aqua from 2002 to 2005). We then average the results over the four instruments. The quantity $\left\langle\mathrm{STOR}_{\mathrm{atmos}}\right\rangle$ is calculated as the finite difference of the vertically integrated temperature and specific humidity from the NCEP reanalysis climatology. As in Donohoe and Battisti (2013), $\langle\mathrm{SHF}\rangle$ is calculated as the residual of radiative heating, atmospheric storage, and the atmospheric heat transport divergence (from NCEP reanalysis).

The seasonal amplitude and phase used in our analysis are defined as the amplitude and phase of the annual harmonic.

\section{2) Results}

A scatterplot of the monthly average $P_{\text {CENT }}$ versus $\mathrm{AHT}_{\mathrm{EQ}}$ and $\triangle \mathrm{SST}$ is shown in Fig. 3. The precipitation centroid varies from $5.3^{\circ} \mathrm{S}$ in February to $7.2^{\circ} \mathrm{N}$ in August and has an annual average of $1.65^{\circ} \mathrm{N}$. This seasonal cycle of ITCZ location is slightly damped (equatorward) of other common metrics of ITCZ location (e.g., the latitude of maximum zonal mean precipitation, Xian and Miller 2008). It can be seen that $P_{\text {CENT }}$ spends four months of the year in the Southern Hemisphere during the austral

\footnotetext{
${ }^{3}$ In this framework, the net flux into the ocean is $\mathrm{SW}_{\mathrm{NET}, \mathrm{SURF}}-$ $\mathrm{SHF}=\mathrm{OHT}+S$.
}
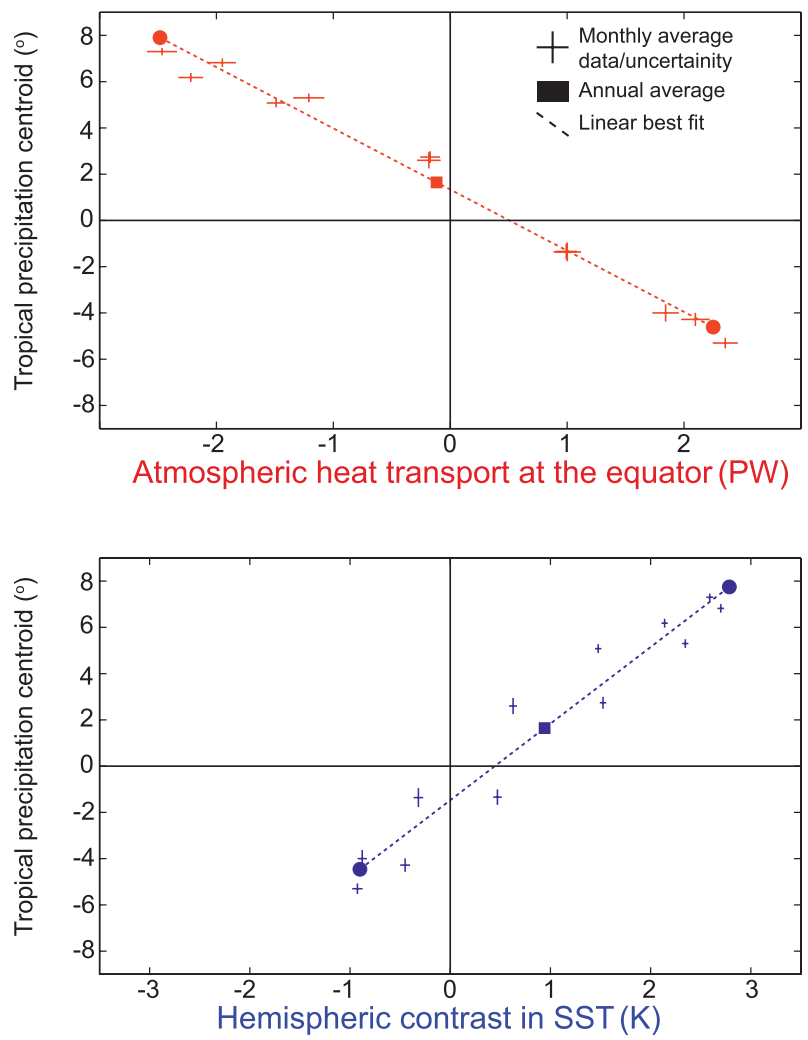

FIG. 3. (top) Scatterplot of the seasonal cycle of tropical precipitation centroid vs cross-equatorial atmospheric heat transport. Each cross is centered on the monthly average and the length of the cross on each axis represents the $95 \%$ confidence interval assessed from the interannual variability. The filled box is the annual average. The dashed line is the linear best fit to the monthly averages. (bottom) As at top, but for the tropical precipitation centroid vs the interhemispheric difference in tropical SST.

summer as the most intense precipitation is found in the South Pacific convergence zone at this time of year (not shown) and the zonal mean precipitation maximum moves to southern latitudes. We note that although the marine ITCZ defined in the eastern Pacific and Atlantic by Waliser and Gautier (1993) never moves south of the equator, the global ITCZ defined in the same study does move into the Southern Hemisphere and agrees very well with our precipitation centroid.

The value of $\mathrm{AHT}_{\mathrm{EQ}}$ varies from 2.1 PW northward in February to 2.3 PW southward in August with an annual average of $0.1 \mathrm{PW}$ southward. The vast majority (over $99 \%$ ) of the seasonal variations in cross-equatorial atmospheric heat transport are associated with the zonal and time averaged meridional overturning circulation at the equator (i.e., the Hadley cell), which reverses seasonally (Dima and Wallace 2003). The seasonal variations in cross-equatorial heat transport associated with the stationary and transient eddies are two orders of magnitude smaller in magnitude (not shown). The 
hemispheric contrast of tropical SST, $\Delta \mathrm{SST}$, has a maximum value of $2.7 \mathrm{~K}$ in September and a minimum of $-0.9 \mathrm{~K}$ in March; it lags the insolation by approximately 3 months and lags both $P_{\mathrm{CENT}}$ and $\mathrm{AHT}_{\mathrm{EQ}}$ by approximately one month. The annual average $\Delta$ SST value is $0.9 \mathrm{~K}$, which corresponds with the maximum tropical SSTs being located north of the equator in the annual average.

The seasonal variations in $P_{\mathrm{CENT}}$ and $\mathrm{AHT}_{\mathrm{EQ}}$ are strongly anticorrelated (as anticipated from Fig. 1) with an $R^{2}$ value of 0.99 and a slope of $-2.7 \pm 0.6^{\circ} \mathrm{PW}^{-1}$. This result suggests that seasonal migrations in both $P_{\mathrm{CENT}}$ and $\mathrm{AHT}_{\mathrm{EQ}}$ primarily reflect the seasonal migration of the Hadley cell. This interpretation is also supported by analysis of the seasonal migration of the overturning streamfunction and the partitioning of $\mathrm{AHT}_{\mathrm{EQ}}$ into latent, sensible, and potential components (not shown); the total $\mathrm{AHT}_{\mathrm{EQ}}$ is always of the same sign as the potential energy heat transport and is opposed by the sensible and latent heat transport as would be expected from a thermally direct circulation in a stably stratified column with moisture and temperature decreasing with height. The linear best fit in Fig. 3 passes close to but not through the origin with a $y$ intercept of $1.2^{\circ} \mathrm{N}$. This offset is not anticipated from our idealized model presented in the introduction and suggests that, although the vast majority of seasonal variations in $P_{\mathrm{CENT}}$ and $\mathrm{AHT}_{\mathrm{EQ}}$ are explained by meridional shifts in the Hadley cell, other phenomena influence either the precipitation and/or atmospheric heat transport. We speculate that monsoonal circulations that are related to zonal inhomogeneities in coastlines and atmospheric circulations - and are thus poorly captured by our zonal average analysis-may bias the precipitation centroid farther north than what would be defined from the Hadley cell-related precipitation only.

Seasonal variations in $P_{\mathrm{CENT}}$ and $\Delta$ SST are strongly correlated (note that the green $\Delta$ SST $x$ axis in Fig. 3 has been inverted) with an $R^{2}$ value of 0.94 and a slope of $3.3^{\circ} \mathrm{K}^{-1}$. The seasonal correlation between $P_{\text {CENT }}$ and $\Delta$ SST is slightly smaller than that between $P_{\mathrm{CENT}}$ and $\mathrm{AHT}_{\mathrm{EQ}}$ because $\Delta \mathrm{SST}$ lags the other two variables by approximately 1 month, leading to an elliptical pattern in the $\Delta \mathrm{SST}$ (green crosses) scatterplot whereas the $\mathrm{AHT}_{\mathrm{EQ}}$ (red crosses) scatterplot falls nearly on the linear best fit. The $y$ intercept of the linear best fit between $P_{\mathrm{CENT}}$ and $\Delta \mathrm{SST}$ is $-1.4^{\circ}$ and is not anticipated a priori. Rather, one might suppose that, if SST determined ITCZ location, a SST distribution that is symmetric about the equator $(\Delta \mathrm{SST}=0)$ would lead to an ITCZ on the equator $\left(P_{\mathrm{CENT}}=0\right)$. Instead, the observations suggest that the ITCZ is located south of the equator when there is no interhemispheric contrast of tropical SSTs. The cause of this offset from the origin in the observations is unclear to us.

Seasonal variations in $\mathrm{AHT}_{\mathrm{EQ}}$ are driven by hemispheric asymmetries in energy input into the atmosphere and can be diagnosed from Eqs. (4) and (5). Ultimately, seasonal variations in $\mathrm{AHT}_{\mathrm{EQ}}$ result from the seasonal migration of the insolation maximum between the hemispheres although the vast majority of the seasonal variations in insolation are stored in the ocean (Fasullo and Trenberth 2008); the hemispheric asymmetry of net shortwave flux at the TOA [ $\left\langle\mathrm{SW}_{\mathrm{NET}, \mathrm{TOA}}\right\rangle$ in Eq. (4)] has a seasonal amplitude of $22.4 \mathrm{PW}$ and is primarily $(83 \%)$ balanced by the hemispheric asymmetry of ocean heat storage $(\langle\mathrm{OHT}+S\rangle)$ with a seasonal magnitude of 18.5 PW out of phase with insolation. Therefore, we chose to recast the interhemispheric contrast of the atmospheric energy budget in terms of the absorption of shortwave radiation in the atmosphere ( $\langle\mathrm{SWABS}\rangle)$ and the nonsolar exchange of energy between the surface and the atmosphere ( $\langle\mathrm{SHF}\rangle)$ as expressed in Eq. (5) (Donohoe and Battisti 2013). The seasonal cycle of the interhemispheric contrast in the atmospheric energy fluxes is shown in Fig. 4.

The summer hemisphere absorbs more shortwave radiation in the atmospheric column than the winter hemisphere and, in the absence of compensating energy fluxes, would result in a 7.1-PW seasonal amplitude of $\mathrm{AHT}_{\mathrm{EQ}}$ with northward heat transport peaking near (5 days after) the austral summer solstice. However, $46 \%$ of this interhemispheric energy contrast is balanced by air-surface energy exchange $(\langle\mathrm{SHF}\rangle)$ with the atmosphere warming the ocean in the summer hemisphere and the ocean heating the atmosphere in the winter hemisphere. Additionally, $16 \%$ of the seasonal variations in $\langle\mathrm{SWABS}\rangle$ is radiated to space as an interhemispheric contrast in OLR $(\langle\mathrm{OLR}\rangle)$. Both $\langle\mathrm{SHF}\rangle$ and $\langle\mathrm{OLR}\rangle$ are nearly antiphased with the insolation and $\langle$ SWABS $\rangle$ (with a phase lead of 1 day and phase lag of 12 days, respectively). The interhemispheric contrast of atmospheric energy storage ( $\left.\left\langle\mathrm{STOR}_{\mathrm{ATMO}}\right\rangle\right)$ has a seasonal amplitude of 2.3 PW and is associated with the heating (in the extratropics) and moistening (in the tropics) of the atmospheric column in the summer hemisphere and the cooling and drying of the column in the winter hemisphere. It leads the insolation by approximately 60 days, which is expected from a system where the negative feedbacks (OLR and atmospheric heat transport) are substantially stronger than the thermal inertia (Donohoe and Battisti 2012). As a consequence, the sum of all the other energy fluxes, which is equal to $\mathrm{AHT}_{\mathrm{EQ}}$ by Eq. (5), is substantially smaller than $\langle\mathrm{SWABS}\rangle$ (due to the damping by $\langle\mathrm{SHF}\rangle$ and $\langle\mathrm{OLR}\rangle$ ) and lags the insolation (due to the phase lead of atmospheric energy 


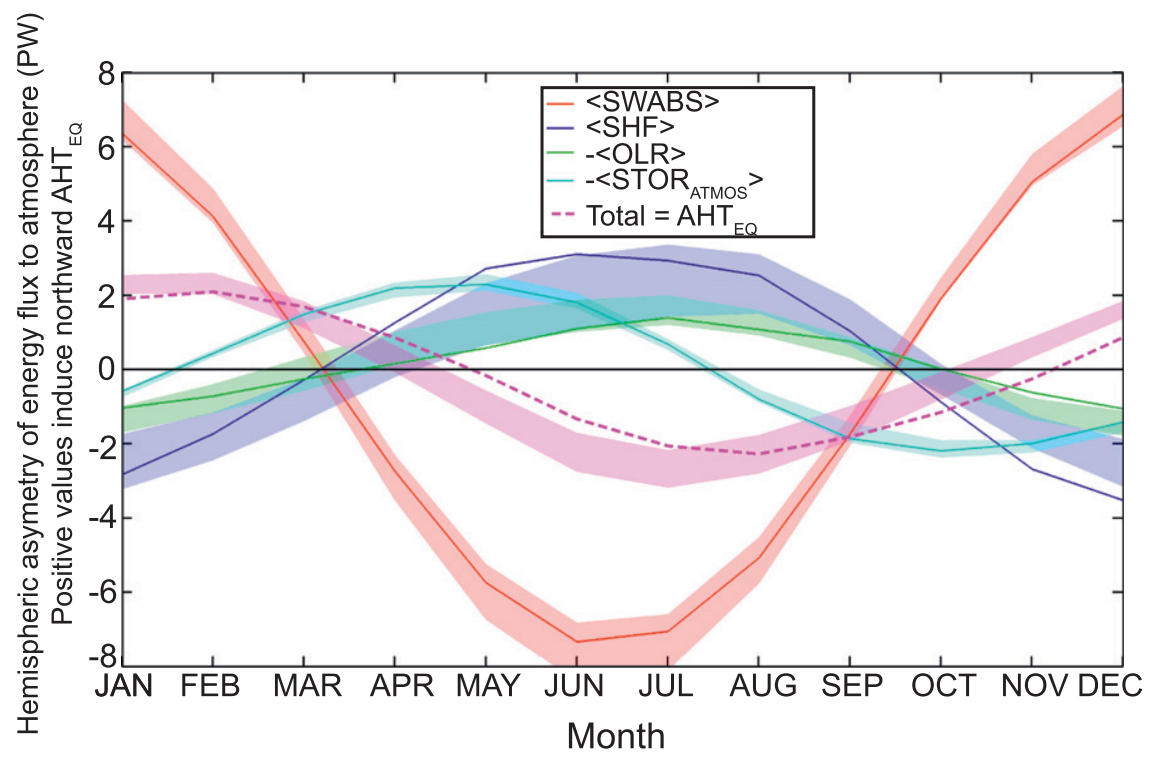

FIG. 4. Seasonal cycle of hemispheric contrast in energy fluxes defined as half the difference in spatial integral of fluxes in the SH minus that in the NH. The solid lines are the observations and the shaded region represents \pm 1 standard deviation about the CMIP3 PI ensemble average. The terms are defined in the legend and discussed in the text in reference to Eq. (5). The first four terms in the legend sum to yield $\mathrm{AHT}_{\mathrm{EQ}}$.

storage, $\left.\left\langle\mathrm{STOR}_{\mathrm{ATMOS}}\right\rangle\right) ; \mathrm{AHT}_{\mathrm{EQ}}$ has a seasonal amplitude of $2.2 \mathrm{PW}$ and lags the insolation by 46 days.

\section{3) THE QuANTITATIVE RELATIONSHIP BETWEEN ITCZ LOCATION AND ATMOSPHERIC HEAT TRANSPORT ACROSS THE EQUATOR}

Figure 3 suggests that the ITCZ location $\left(P_{\mathrm{CENT}}\right)$ covaries with the atmospheric heat transport across the equator $\left(\mathrm{AHT}_{\mathrm{EQ}}\right)$ with a 1-PW change in $\mathrm{AHT}_{\mathrm{EQ}}$ corresponding to a $2.7^{\circ}$ meridional shift in the ITCZ location. To put this quantitative relationship in perspective, we remind the reader that the observed annual mean $\mathrm{AHT}_{\mathrm{EQ}}$ is $-0.1 \mathrm{PW}$ and that the maximum value of AHT at all latitudes is on the order of 5 PW (Trenberth and Caron 2001). This quantitative relationship suggests that modest shifts in tropical precipitation must be accompanied by fairly substantial perturbations to the interhemispheric energy budget (Fig. 2), the focus of this manuscript. We now ask this question: What physical processes set the quantitative relationship between $P_{\mathrm{CENT}}$ and $\mathrm{AHT}_{\mathrm{EQ}}$ ?

If the atmospheric heat transport in the tropics is dominated by the Hadley cell, then $\mathrm{AHT}_{\mathrm{EQ}}$ is proportional to the mass overturning streamfunction $(\Psi)$ at the equator-defined as positive when the motion in the upper branch is northward-times the average energy contrast between the poleward and equatorward flow $\left(\Delta T_{E}\right.$; see Czaja and Marshall 2006):

$$
\mathrm{AHT}_{\mathrm{EQ}} \approx \Psi_{\mathrm{EQ}} c_{p} \Delta T_{E}
$$

Indeed, the monthly average overturning streamfunction at $500 \mathrm{hPa}$ over the equator is highly correlated $\left(R^{2}=0.99\right)$ with $\mathrm{AHT}_{\mathrm{EQ}}$ with a regression coefficient of $0.014 \mathrm{PW} \mathrm{Sv}^{-1}$ (top panel of Fig. 5). The regression coefficient corresponds to an equivalent potential temperature contrast between the poleward and equatorward moving air $\Delta T_{E}$ of $14 \mathrm{~K}$ and is consistent with a meridional overturning circulation that is on the order of $600 \mathrm{hPa}$ deep given the average vertical profile of temperature and moisture in the tropics. This result suggests that seasonal variations of $\Psi_{\mathrm{EQ}}$ control $\mathrm{AHT} \mathrm{EQ}_{\mathrm{EQ}}$ while $\Delta T_{E}$ remains fairly constant. If $\Delta T_{E}$ is constant, then we can derive a relationship between the latitude of zero mass overturning $\left(\theta_{\Psi=0}\right)$ and the $\mathrm{AHT}_{\mathrm{EQ}}$ by use of a Taylor expansion of the overturning streamfunction about its zero crossing and Eq. (8):

$$
\mathrm{AHT}_{\mathrm{EQ}} \approx-\left.\theta_{\Psi=0} \frac{\partial \Psi}{\partial \theta}\right|_{\theta_{\Psi=0}} c_{p} \Delta T_{E} .
$$

The expected relationship between $\theta_{\Psi=0}$ and $\mathrm{AHT}_{\mathrm{EQ}}$ from Eq. (9) [using $\Delta T_{E}$ of $14 \mathrm{~K}$ and the climatological mean of $\partial \Psi /\left.\partial \theta\right|_{\theta_{\Psi=0}}$ of $8 \mathrm{~Sv}\left({ }^{\circ}\right)^{-1}$; here $1 \mathrm{~Sv}$ is defined as $1 \times 10^{9} \mathrm{~kg} \mathrm{~s}^{-1}$ as in Czaja and Marshall (2006)] is shown by the black dashed line in the bottom panel of Fig. 5: it has a slope of $-8.9^{\circ} \mathrm{PW}^{-1}$. This expectation compares 

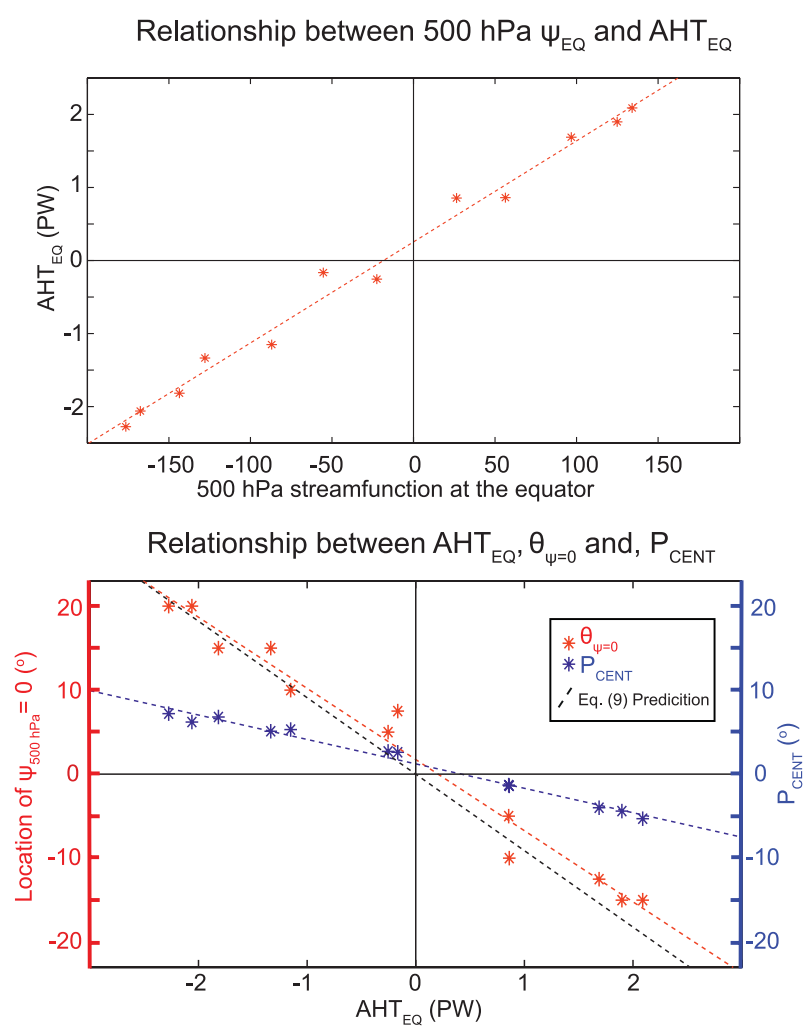

FIG. 5. (top) Scatterplot of $\mathrm{AHT}_{\mathrm{EQ}}$ vs the mass overturning streamfunction at $500 \mathrm{hPa}$ over the equator over the seasonal cycle in the observations. Each asterisk is a monthly average and the dashed line is the linear best fit. (bottom) Scatterplot of the location of the 0 mass overturning streamfunction $\theta_{\Psi=0}$ at $500 \mathrm{hPa}$ vs $\mathrm{AHT}_{\mathrm{EQ}}$ (red asterisk and linear best fit dashed line) and $P_{\mathrm{CENT}} \mathrm{vs}$ $\mathrm{AHT}_{\mathrm{EQ}}$ (blue asterisk and linear best fit dashed line). The expected relationship between $\theta_{\Psi=0}$ and $\mathrm{AHT}_{\mathrm{EQ}}$ from Eq. (9) is shown by the dashed black line.

well with the monthly average values of $\theta_{\Psi=0}$ and $\mathrm{AHT}_{\mathrm{EQ}}$ (red asterisks in the lower panel Fig. 5), suggesting that $\partial \Psi / \partial \theta$ is fairly spatially uniform in the tropics. Equation (9) is useful because, if the maximum ascent and precipitation occurs where the mass overturning streamfunction changes sign $\left(\theta_{\Psi=0}\right)$, then we would expect $P_{\mathrm{CENT}}$ and $\mathrm{AHT}_{\mathrm{EQ}}$ to follow the same relationship as that found between $\theta_{\Psi=0}$ and $\mathrm{AHT}_{\mathrm{EQ}}$ (i.e., approximately $-8.9^{\circ} \mathrm{PW}^{-1}$ ). However, the slope between $P_{\mathrm{CENT}}$ and $\mathrm{AHT}_{\mathrm{EQ}}$ is substantially smaller $\left(-2.7^{\circ} \mathrm{PW}^{-1}\right.$; blue asterisks in the lower panel of Fig. 5), suggesting that $\mathrm{P}_{\mathrm{CENT}}$ remains substantially equatorward of the zero streamfunction as the Hadley cell seasonally moves off the equator. Lindzen and Hou (1988) previously found that the maximum upward ascent occurs equatorward of the location of zero streamfunction in an idealized model of the Hadley circulation; we will return to a discussion of this point in section $2 \mathrm{c}(2)$.

\section{b. Coupled climate models}

\section{1) Model Runs used AND Methodology}

We use model output from phase 3 of the Coupled Model Intercomparison Project (CMIP3) multimodel database (Meehl et al. 2007): an ensemble of standardized coupled climate simulations from 25 different climate models that were used in the Intergovernmental Panel on Climate Change's Fourth Assessment Report. We analyze the preindustrial (PI) simulations here. In those simulations, greenhouse gas concentrations, aerosols, and solar forcing are fixed at preindustrial levels and the models are run for 400 years. The last 20 years of the PI simulations are used to calculate climatological fields. The 16 models used in this study are listed in Table 1.

The turbulent and radiative energy fluxes at the surface and TOA are provided as model output fields. This allows $\langle\mathrm{SWABS}\rangle$ and $\langle\mathrm{SHF}\rangle$ to be directly calculated from Eqs. (6) and (7). The $\langle\mathrm{OLR}\rangle$ is directly calculated and $\left\langle\right.$ STOR $\left._{\text {ATMOS }}\right\rangle$ is calculated from finite difference of the monthly averaged vertically integrated temperature and specific humidity fields; $\mathrm{AHT}_{\mathrm{EQ}}$ is then calculated from the residual of the other terms in Eq. (5).

\section{2) RESUlts}

We show the seasonal amplitude (given by half the length of the line) and the regression coefficient (given by the slope of the line) between $P_{\mathrm{CENT}}$ and $\mathrm{AHT}_{\mathrm{EQ}}$ for each CMIP3 ensemble member in the upper panel of Fig. 6. We define the seasonal amplitude of $P_{\text {CENT }}$ and $\mathrm{AHT}_{\mathrm{EQ}}$ as the amplitude of the annual harmonic of each variable. The CMIP3 ensemble mean regression coefficient between $P_{\mathrm{CENT}}$ and $\mathrm{AHT}_{\mathrm{EQ}}$ is $-2.4^{\circ} \pm 0.4^{\circ} \mathrm{PW}^{-1}$ (the slope of the thick black line) and is slightly smaller but statistically indistinguishable from the value of $-2.7^{\circ} \pm 0.6^{\circ} \mathrm{PW}^{-1}$ found in the observations (the thick purple line). Table 2 lists the seasonal statistics of $P_{\text {CENT }}$ and $\mathrm{AHT}_{\mathrm{EQ}}$ in observations and the models. Seasonal variations in $P_{\mathrm{CENT}}$ and $\mathrm{AHT}_{\mathrm{EQ}}$ are significantly correlated with each other in all models with an ensemble average correlation coefficient of -0.89 . On average, the linear best fits in the models come closer to the origin than do the observations (thick black line in Fig. 6), conforming to our idealized expectation that when the precipitation is centered on the equator, the ascending branch of the Hadley cell will also be on the equator, resulting in zero cross-equatorial heat transport in the atmosphere. The relationship between $P_{\text {CENT }}$ and $\mathrm{AHT}_{\mathrm{EQ}}$ over the seasonal cycle is fairly consistent from one model to the next (all the slopes in Fig. 6 are similar) and is similar to the relationship found in the observations. This suggests that fairly robust physics underlie the relationship between $P_{\mathrm{CENT}}$ and $\mathrm{AHT}_{\mathrm{EQ}}$, mainly the 
TABLE 1. Models used in this study and their resolution. The horizontal resolution refers to the latitudinal and longitudinal grid spacing or the spectral truncation. The vertical resolution is the number of vertical levels.

\begin{tabular}{|c|c|c|c|}
\hline Abbreviation & Full name & $\begin{array}{l}\text { Horizontal } \\
\text { resolution }\end{array}$ & $\begin{array}{l}\text { Vertical } \\
\text { resolution }\end{array}$ \\
\hline BCCR-BCM2.0 & $\begin{array}{l}\text { Bjerknes Centre for Climate Research (University of Bergen, } \\
\text { Norway) Bergen Climate Model, version } 2\end{array}$ & T63 & L31 \\
\hline CCCMA-CGCM3.1 & $\begin{array}{l}\text { Canadian Centre for Climate Modeling and Analysis (Canada) } \\
\text { Coupled General Circulation Model, version } 3.1\end{array}$ & T47 & L31 \\
\hline CNRM-CM3 & $\begin{array}{l}\text { Centre National de Recherches Météorologiques (France) } \\
\text { Coupled Global Climate Model, version } 3\end{array}$ & T63 & $\mathrm{L} 45$ \\
\hline CSIRO-Mk3.0 & $\begin{array}{l}\text { Commonwealth Scientific and Research Organization } \\
\text { (Australia) Mark } 3.0\end{array}$ & T63 & L18 \\
\hline GFDL-CM2.0 & $\begin{array}{l}\text { Geophysical Fluid Dynamics Laboratory (United States) } \\
\text { Climate Model, version } 2.0\end{array}$ & $2.0^{\circ} \times 2.5^{\circ}$ & L24 \\
\hline GFDL-CM2.1 & GFDL (United States) Climate Model, version 2.1 & $2.0^{\circ} \times 2.5^{\circ}$ & L24 \\
\hline IAP-FGOALS & $\begin{array}{l}\text { Institute of Atmospheric Physics [National Key } \\
\text { Laboratory of Numerical Modeling for Atmospheric } \\
\text { Sciences and Geophysical Fluid Dynamics (LASG), China] } \\
\text { Flexible Global Ocean-Atmosphere-Land System Model }\end{array}$ & $\mathrm{T} 42$ & L26 \\
\hline MPI-ECHAM5 & Max Planck Institute for Meteorology (Germany) ECHAM & T63 & L31 \\
\hline INM-CM3.0 & $\begin{array}{l}\text { Institute for Numerical Mathematics (Russia) Coupled } \\
\text { Model, version 3.0 }\end{array}$ & $4^{\circ} \times 5^{\circ}$ & L21 \\
\hline IPSL-CM4.0 & $\begin{array}{l}\text { L'Institute Pierre Simon Laplace (France) Coupled } \\
\text { Model, version } 4\end{array}$ & $2.5^{\circ} \times 3.75^{\circ}$ & L19 \\
\hline MIROC3.2(medres) & $\begin{array}{l}\text { National Institute for Environmental Studies (NIES) and Frontier } \\
\text { Research Center for Global Change (FRCGC; Japan) Model } \\
\text { for Interdisciplinary Research on Climate (MIROC) 3.2, } \\
\text { medium-resolution version }\end{array}$ & $\mathrm{T} 42$ & L20 \\
\hline MIROC3.2(hires) & NIES and FRCGC (Japan) MIROC 3.2, high-resolution version & T106 & L56 \\
\hline MRI-CGCM2.3.2a & $\begin{array}{l}\text { Meteorological Research Institute (Japan) Coupled General } \\
\text { Circulation Model, version 2.3.2a }\end{array}$ & $\mathrm{T} 42$ & L30 \\
\hline NCAR-CCSM3.0 & $\begin{array}{l}\text { National Center for Atmospheric Research (United States) Community } \\
\text { Climate System Model, version } 3.0\end{array}$ & T85 & L26 \\
\hline UKMO-HadCM3 & $\begin{array}{l}\text { Hadley Centre for Climate Prediction and Research (United Kingdom), } \\
\text { third climate configuration of the Met Office Unified Model }\end{array}$ & $2.5^{\circ} \times 3.8^{\circ}$ & L19 \\
\hline MIUB-ECHOg & $\begin{array}{l}\text { Meteorological Institute of the University of Bonn } \\
\text { (Germany) ECHAM and the global Hamburg Ocean } \\
\text { Primitive Equation }\end{array}$ & $\mathrm{T} 30$ & L19 \\
\hline
\end{tabular}

mutual relationship among the tropical precipitation maximum, $\mathrm{AHT}_{\mathrm{EQ}}$, and the location of the Hadley cell. The precipitation centroid lags the cross-equatorial atmospheric heat transport in the models by 29 days in the ensemble average (with a standard deviation of 6 days). This is in contrast to the observations where there is virtually no $\left(<2\right.$ days) phase shift between $P_{\text {CENT }}$ and $\mathrm{AHT}_{\mathrm{EO}}$. We further discuss this result later in this section.

We note that the intermodel spread of the annual mean $P_{\mathrm{CENT}}$ and $\mathrm{AHT}_{\mathrm{EQ}}$ are significantly correlated with each other with a regression coefficient of -0.79 and a slope that is statistically indistinguishable from the ensemble mean seasonal relationship between $P_{\mathrm{CENT}}$ and $\mathrm{AHT}_{\mathrm{EQ}}$. This result suggests that the same physics that determine the seasonal migration of the ITCZ location and $\mathrm{AHT}_{\mathrm{EQ}}$ (associated with meridional shifts in the Hadley cell) also govern the intermodel spread of ITCZ location in the annual mean. Although there are slight variations in the relationship between $P_{\mathrm{CENT}}$ and $\mathrm{AHT}_{\mathrm{EQ}}$ between the different models and the observations, the robust relationship between $P_{\mathrm{CENT}}$ and $\mathrm{AHT}_{\mathrm{EQ}}$ allows one to predict $P_{\mathrm{CENT}}$ from $\mathrm{AHT}_{\mathrm{EQ}}$ (or vice versa) with the same relationship holding for the seasonal problem and for the annual mean intermodel spread problem.

Histograms of the monthly mean $P_{\mathrm{CENT}}$ over the last 150 years of the simulations are shown in Fig. 7. The $P_{\text {CENT }}$ distribution in each model is bimodal; $P_{\text {CENT }}$ is most often found in one of the two solstitial extremes (Lindzen and Hou 1988) and is rarely found in the vicinity of the annual average. By construction, the annual average is the average of the northernmost and southernmost extent shown by the shaded dots in Fig. 7 (and defined as the annual mean plus or minus the seasonal amplitude). Therefore, in order to shift the annual average $P_{\mathrm{CENT}}$ northward, the ITCZ must either migrate farther into (or stay longer in) the Northern Hemisphere in the boreal 
TABLE 2. Seasonal amplitude (amplitude of the annual harmonic) and regression coefficients of precipitation centroid, $\mathrm{AHT}_{\mathrm{EQ}}$, and $\Delta \mathrm{SST}$ in the observations and in CMIP3 preindustrial models. The $95 \%$ confidence limits are listed after each value and are assessed from the interannual spread in the observations, intermodel spread in the models, and uncertainty in the regression coefficients.

\begin{tabular}{lcc}
\hline \hline & Observations & $\begin{array}{c}\text { CMIP3 ensemble } \\
\text { mean }\end{array}$ \\
\hline $\begin{array}{l}\text { Centroid seasonal } \\
\text { amplitude }\left({ }^{\circ}\right)\end{array}$ & $6.3 \pm 0.2$ & $6.6 \pm 0.8$ \\
$\mathrm{AHT}_{\mathrm{EQ}}$ seasonal & $2.2 \pm 0.1$ & $2.5 \pm 0.3$ \\
$\quad$ amplitude $(\mathrm{PW})$ & $1.8 \pm 0.1$ & $2.0 \pm 0.3$ \\
$\Delta \mathrm{SST}$ & $-2.7 \pm 0.6$ & $-2.4 \pm 0.4$ \\
$P_{\mathrm{CENT}}$ vs $\mathrm{AHT}$ & & \\
$\quad$ regression coef $\left({ }^{\circ} \mathrm{PW}^{-1}\right)$ & $3.3 \pm 0.6$ & $3.7 \pm 0.7$ \\
$P_{\mathrm{CENT}}$ vs $\Delta \mathrm{SST}$ & & \\
$\quad$ regression coef $\left({ }^{\circ} \mathrm{K}^{-1}\right)$ & & \\
\hline
\end{tabular}

summer or migrate less far into (or spend less time in) the Southern Hemisphere during the austral summer. The models with an anomalous (relative to the ensemble average) northward annual mean $P_{\text {CENT }}$ (the models shown in red toward the top of the figure) tend to have a $P_{\text {CENT }}$ that migrates farther north in the boreal summer. In contrast, the models with a southward annual mean $P_{\text {CENT }}$ (the models shown in blue toward the bottom of the figure) tend to have a $P_{\text {CENT }}$ that migrates less far north in the boreal summer. Similarly, the magnitude of the southward migration of the ITCZ during the austral winter is largest in the models with an annual mean ITCZ location south of the ensemble average (blue dots) and smallest in the models with an annual mean ITCZ location north of the ensemble mean (red dots). We further discuss the relationship between the seasonal extremes and the annual mean of $P_{\mathrm{CENT}}$ and $\mathrm{AHT}_{\mathrm{EQ}}$ in section 4.

The seasonal amplitude of $\mathrm{AHT}_{\mathrm{EQ}}$ is $2.5 \pm 0.3 \mathrm{PW}$ in the models and is larger but within the error bars of that found in the observations (2.2 PW; Table 2). As a consequence, the seasonal amplitude in $P_{\mathrm{CENT}}$ of $6.6^{\circ} \pm 0.8^{\circ}$ is also larger than that in the observations $\left(6.3^{\circ}\right)$. The amplitude and phasing of $\langle\mathrm{SWABS}\rangle,\langle\mathrm{OLR}\rangle$, and $\left\langle\mathrm{STOR}_{\mathrm{ATMO}}\right\rangle$ closely match those found in the observations (cf. the shaded regions and the solid lines in Fig. 4). In contrast, $\langle\mathrm{SHF}\rangle$ in the models lags $\langle\mathrm{SHF}\rangle$ in the observations by 16 days on average. As a result, the net hemispheric contrast in energy input to the atmospheric column is more in phase with the insolation in the models than in the observations and $\mathrm{AHT}_{\mathrm{EQ}}$ lags the insolation by 25 days in the models as compared to 46 days in the observations. This offers a partial explanation for why the seasonal migration of $P_{\mathrm{CENT}}$ lags that in $\mathrm{AHT}_{\mathrm{EQ}}$ in the models (by 29 days) but not in the observations. However, the root cause of this discrepancy and its relationship to the seasonal migration of the Hadley circulation is unclear to us.
The seasonal amplitude and the regression coefficient (given by the slope of the line) between $P_{\mathrm{CENT}}$ and $\triangle$ SST for each CMIP3 ensemble member is shown in the lower panel of Fig. 6 along with the observations. The ensemble average of the seasonal amplitude of $\Delta \mathrm{SST}$ is $2.0 \pm 0.3 \mathrm{~K}$ and compares well with that in the observations $(1.8 \mathrm{~K})$. Seasonal variations in $\Delta \mathrm{SST}$ are highly correlated with seasonal variations in $P_{\mathrm{CENT}}$ in all models with an ensemble mean correlation coefficient of 0.97 . The regression coefficient between $P_{\mathrm{CENT}}$ and $\Delta \mathrm{SST}$ is $3.7^{\circ} \mathrm{K}^{-1}$ in the CMIP3 ensemble average and compares well with that in the observations $\left(3.3^{\circ} \mathrm{K}^{-1}\right)$ but varies significantly (standard deviation of $0.7^{\circ} \mathrm{K}^{-1}$ ) between models (Table 2). These results suggest that the robust relationship between seasonal variations in tropical SST gradients and ITCZ location seen in the observations is also found in coupled climate models.

\section{c. Slab ocean aquaplanet simulations}

The vast majority of seasonal variations in insolation are stored locally in the ocean (see the discussion in section 2a) and thus the seasonal cycle of energy fluxes in the atmosphere hinges critically on the thermal inertia of the ocean. In this subsection, we analyze the seasonal relationship between ITCZ location and cross-equatorial heat transport in the atmosphere by modifying the amplitude of the seasonal cycle in an ensemble of slab ocean aquaplanet simulation in which the ocean depth is varied from 2.4 to $50 \mathrm{~m}$.

\section{1) MODEL RUNS USED}

The model integrations are performed with the Geophysical Fluid Dynamics Laboratory (GFDL) Atmospheric Model version 2.1 (Delworth et al. 2006) featuring a finite-volume dynamical core (Lin 2004) with a horizontal resolution of approximately $2^{\circ}$ latitude and 24 vertical levels. The atmospheric model is coupled to a slab ocean with spatially uniform depth. Five ensemble members with prescribed ocean depths of 2.4, 6, 12, 24, and $50 \mathrm{~m}$ are analyzed in this study. The model is forced by seasonally varying insolation with zero eccentricity and $23.439^{\circ}$ obliquity, and is run for 20 years, sufficient to converge on a steady climatology. The model climatology is taken from the last five years of the integrations.

\section{2) Results}

The seasonal migration of the ITCZ off the equator has a larger amplitude for shallower ocean depths (Fig. 8) and $P_{\mathrm{CENT}}$ reaches as far as $21^{\circ}$ in the $2.4-\mathrm{m}$ slab depth run as compared to $3^{\circ}$ in the $50-\mathrm{m}$ slab depth run. This behavior is expected because the adjustment time scale of a 50-m-deep ocean to solar heating is on the order of one year (Donohoe 2011) as compared to weeks for 
Seasonal cycle of ITCZ location and cross equatorial heat transport in CMIP3 models

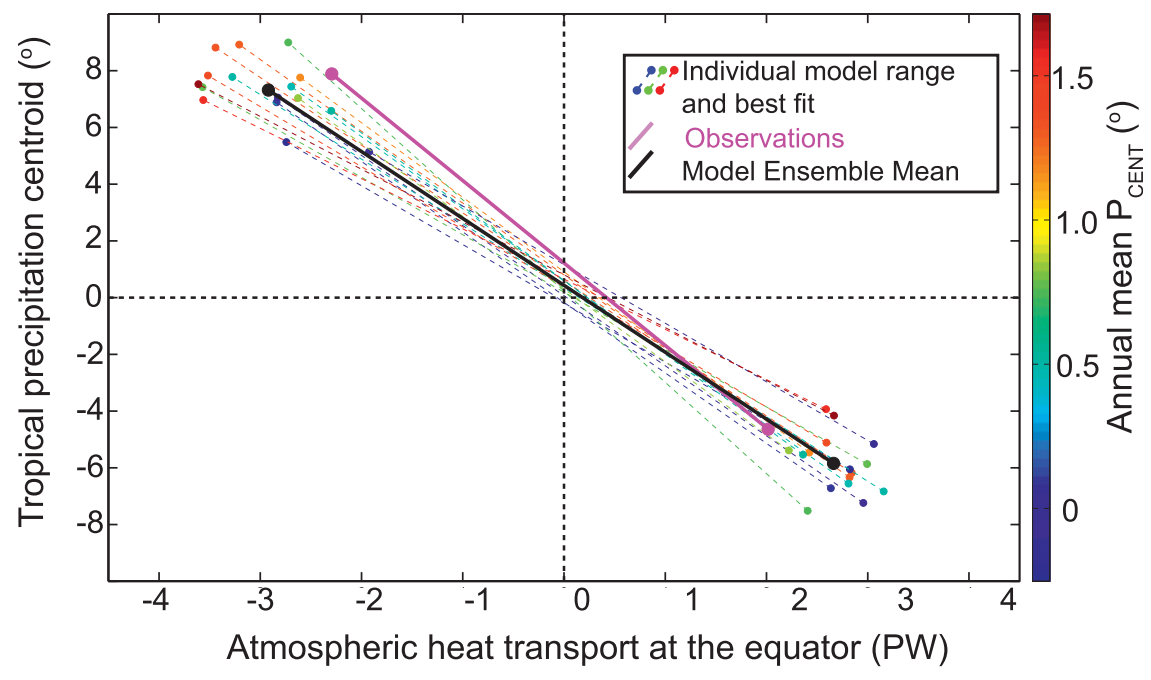

Seasonal cycle of ITCZ location and
tropical SST gradient in CMIP3 models

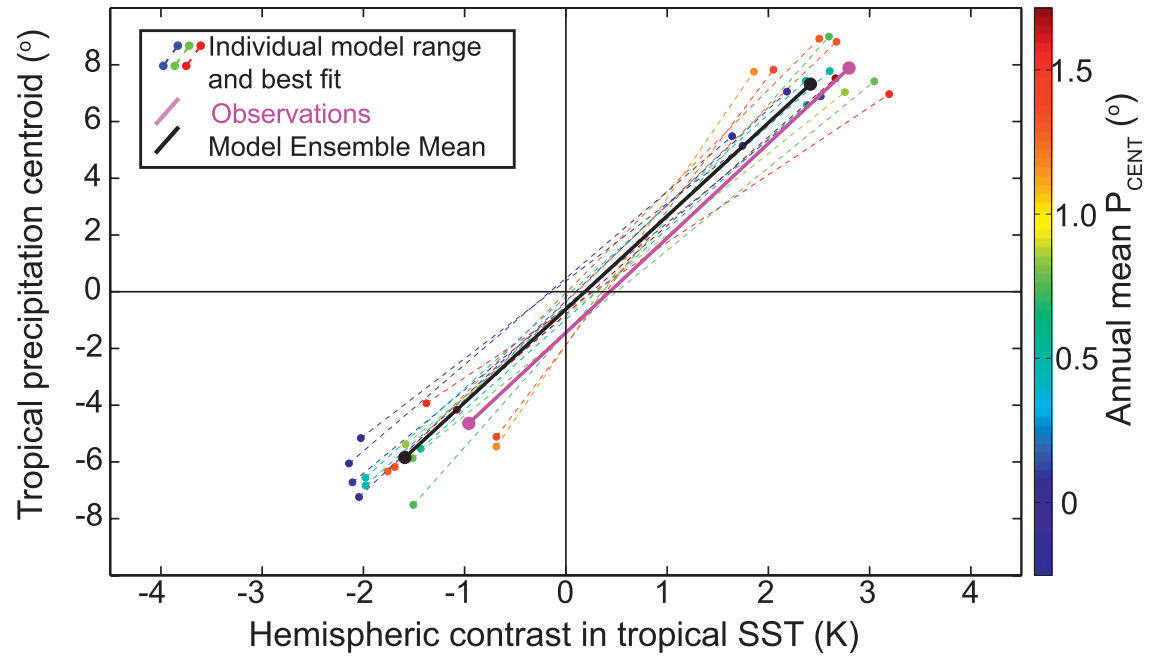

FIG. 6. (top) Seasonal range of precipitation centroid vs atmospheric heat transport at the equator $\left(\mathrm{AHT}_{\mathrm{EQ}}\right)$ in individual CMIP preindustrial models (dashed colored lines with filled dots on each end), the model ensemble mean (thick purple line and filled dots), and the observations (thick black line and filled dots). The seasonal range is twice the amplitude of the annual harmonic of each variable and the slope of the line is the regression coefficient of the monthly data. The models are color coded by their annual average $P_{\text {CENT }}$ with the color scale given by the color bar to the right. (bottom) As at top, but for precipitation centroid vs interhemispheric contrast of tropical SST.

2.4-m-deep ocean. Thus, the SSTs barely adjust to the seasonally varying insolation in the 50-m run while the maximum SST moves seasonally with the insolation in the 2.4-m run.
The seasonal amplitude of $\mathrm{AHT}_{\mathrm{EQ}}$ also decreases with increasing ocean depth, from 11.6 PW in the 2.4-m run to $0.5 \mathrm{PW}$ in the 50-m run. In the shallow ocean run, the SSTs respond rapidly to the seasonally varying 


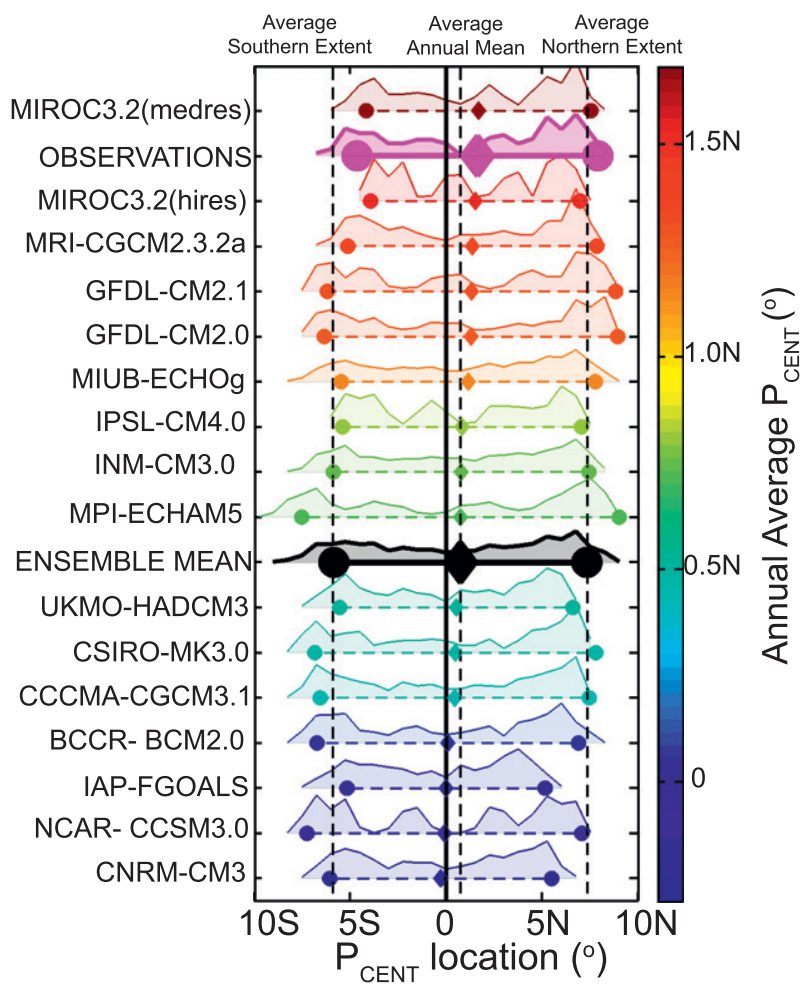

FIG. 7. Histograms of $P_{\text {CENT }}$ in the CMIP3 PI models and observations. The shaded region is the normalized histogram of monthly mean $P_{\text {CENT }}$ and the seasonal range (defined as twice the amplitude of the annual harmonic) of $P_{\mathrm{CENT}}$ is given by the dashed lines attaching the filled dots (representing the climatological northernmost and southernmost extent). The annual average for each model is also shown with the shaded diamond. The models are organized on the $y$ axis and color coded by annual average $P_{\mathrm{CENT}}$ with the same color bar used in Fig. 6. Observations are given by the thick magenta line and the CMIP3 ensemble average is shown in the thick black lines. The vertical dashed black lines are the ensemble average annual mean, northernmost, and southernmost extent $P_{\mathrm{CENT}}$.

insolation, heating up over the summer hemisphere and subsequently fluxing energy upward (via turbulent and longwave fluxes) to the adjacent atmosphere to drive seasonal variations in $\mathrm{AHT}_{\mathrm{EO}}$; in the 2.4-m run $\langle\mathrm{SHF}\rangle$ is nearly in phase with the insolation (11-day lag) and has a seasonal amplitude of 11.6 PW. In contrast, the solar heating of the ocean makes a minimal impact on ocean temperatures in the deep ocean runs due to the large heat capacity of the ocean. In fact, SWABS is the only source of seasonal atmospheric heating in the 50-m run and the atmosphere loses energy to the ocean during the warm season; in the 50-m run $\langle\mathrm{SHF}\rangle$ is nearly antiphased with the insolation (192-day lag) and has a seasonal amplitude of $3.7 \mathrm{PW}$.

Seasonal variations in $P_{\mathrm{CENT}}$ and $\mathrm{AHT}_{\mathrm{EQ}}$ are strongly anticorrelated, with an ensemble average correlation coefficient of -0.95 . The relationship between seasonal variations in $P_{\mathrm{CENT}}$ and $\mathrm{AHT}_{\mathrm{EQ}}$ changes with mixed layer depth (cf. the slopes in Fig. 8). The linear best fit to the monthly averaged data has a slope of $-2.0^{\circ} \mathrm{PW}^{-1}$ in the $2.4-\mathrm{m}$ run and $-6.1^{\circ} \mathrm{PW}^{-1}$ in the $50-\mathrm{m}$ run and varies monotonically with ocean depth for the intermediate depth runs. This result is not expected from our conceptual model of the mutual dependency of the ITCZ location and atmospheric heat transport on meridional shifts in the Hadley cell (Fig. 1). We argue that the decrease in the slope of $P_{\mathrm{CENT}}$ with respect to $\mathrm{AHT}_{\mathrm{EQ}}$ as the ocean depth decreases is a consequence of the following two factors:

1) The maximum upward motion (and convective precipitation) occurs where the meridional gradient of the overturning streamfunction is greatest by the (Boussinesq) continuity equation. For a symmetric Hadley circulation (with summer and winter cells of equal magnitude), the upward motion will be centered about the location of the zero streamfunction. In contrast, in a nonsymmetric Hadley circulation where the winter cell is more intense than the summer cell, the location of maximum streamfunction gradient occurs within the winter cell and the maximum upward motion and precipitation occurs equatorward of where the streamfunction goes to zero. For example, in the 2.4-m run, $P_{\text {CENT }}$ is nearly collocated with the location of maximum streamfunction gradient (cf. the dashed light blue line in the lower panel of Fig. 9 with the dashed green line) for all months and the seasonal migration of the streamfunction zero crossing is nearly twice as large (the dashed black line); the regression coefficient between seasonal variations in the $P_{\text {CENT }}$ and the location of maximum streamfunction gradient is 0.95 whereas the regression coefficient between $P_{\mathrm{CENT}}$ and the streamfunction zero crossing is 0.42 . In contrast, in the $50-\mathrm{m}$ depth run, the ITCZ stays close to the equator and the winter and summer Hadley cells are nearly mirror images of one another. As a consequence, $P_{\text {CENT }}$ is nearly collocated with both the location of maximum streamfunction derivative and the streamfunction zero crossing over the seasonal cycle (regression coefficients of 0.88 and 0.86 , respectively). In summary, the precipitation centroid has less meridional migration than the overturning streamfunction as the ITCZ moves farther from the equator and an asymmetry between the magnitude of the winter and summer cells develops.

2) The winter Hadley cell increases in intensity (relative to the summer cell) as the ITCZ moves farther off the equator. As a consequence, the cross-equatorial 


\section{Seasonal cycle of ITCZ location and cross equatorial heat transport in slab aquaplanet simulations}

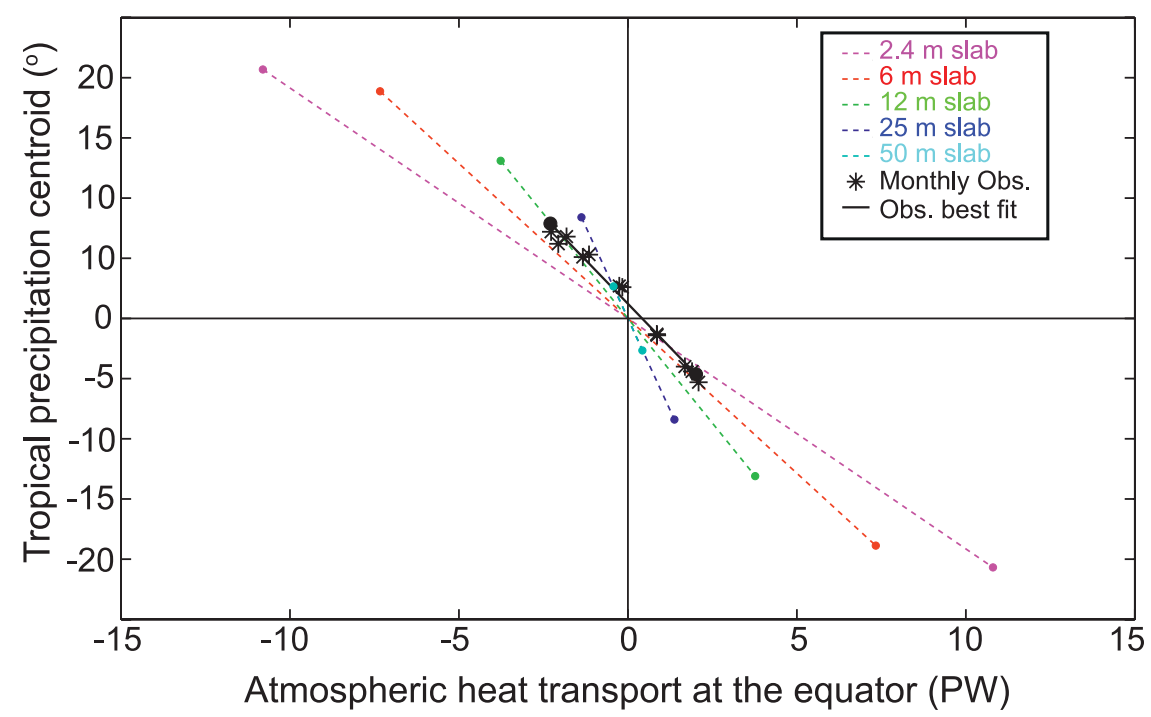

\section{Seasonal cycle of ITCZ location and hemispheric contrast of tropical SST}

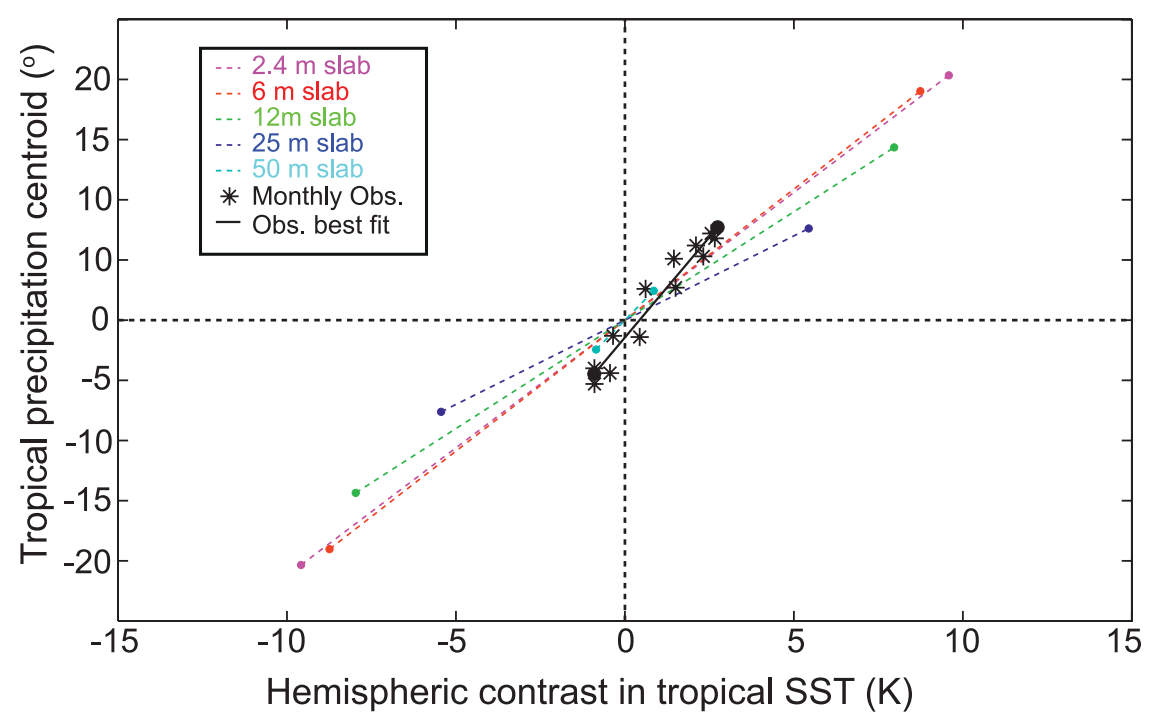

FIG. 8. (top) Seasonal range of precipitation centroid and atmospheric heat transport across the equator in the slab ocean aquaplanet simulations with each simulation (ocean depth) given by a different color. The seasonal range is twice the amplitude of the annual harmonic of each variable and the slope of the line is the regression coefficient of the monthly data. The black asterisks are the monthly observations and the solid black line is the seasonal range of the observations. (bottom) As at top, but for precipitation centroid and tropical SST gradient.

heat transport in the atmosphere changes more than would be expected from meridionally translating the Hadley cell without concurrently changing the structure/intensity of the cells as the ITCZ moves off the equator.
As a result of the two above factors, when the ITCZ moves farther from the equator (and the winter cell intensifies relative to the summer cell), the precipitation centroid moves less than would be expected from meridionally translating the Hadley circulation and the heat 


\section{Summer streamfunction and precipitation}
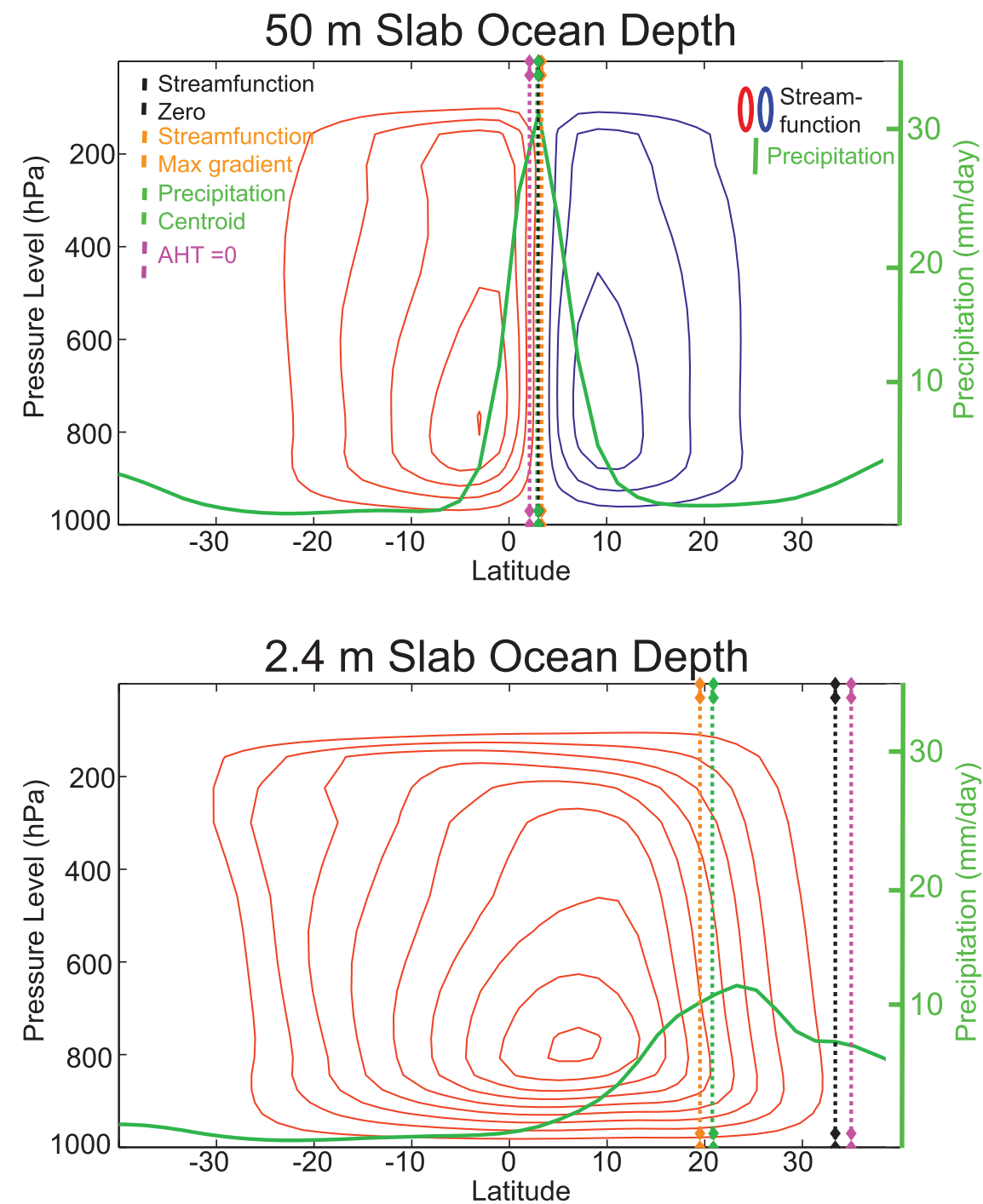

FIG. 9. Boreal summer meridional overturning streamfunction in the atmosphere (red and blue contours with a contour interval of $50 \mathrm{~Sv}$ ) coplotted with the zonal mean precipitation (solid green lines). Also shown is the precipitation centroid (dashed green line), the location where the AHT is 0 (dashed purple line), the location of the 0 streamfunction at $600 \mathrm{hPa}$ (dashed black line), and the location of maximum streamfunction gradient at $600 \mathrm{hPa}$ (dashed orange line). The top panel is 50-m slab ocean run and the bottom panel is the 2.4-m slab ocean run.

transport across the equator changes more than would be expected. The net result is that the slope of $P_{\mathrm{CENT}}$ with respect to $\mathrm{AHT}_{\mathrm{EQ}}$ decreases as the ITCZ moves off the equator. Indeed, in the 2.4-m slab depth simulation, the relationship between $P_{\mathrm{CENT}}$ and $\mathrm{AHT}_{\mathrm{EQ}}$ follows the same steep sloped line found in the $50-\mathrm{m}$ run for the transition (fall and spring) months when the ITCZ crosses the equator (not shown).

The relationship between $P_{\mathrm{CENT}}$ and $\mathrm{AHT}_{\mathrm{EQ}}$ in the observations is coplotted with the slab ocean aquaplanet simulations in Fig. 8. The slope found in the observations is very close to that of the 24-m depth run while the seasonal amplitude of $P_{\mathrm{CENT}}$ and $\mathrm{AHT}_{\mathrm{EQ}}$ in the observations falls somewhere between that in the $6-\mathrm{m}$ and $12-\mathrm{m}$ runs. We will return to a discussion of these points in section 4 .

The seasonal amplitude of $\Delta$ SST increases with decreasing slab ocean depth, from $0.9 \mathrm{~K}$ in the $50-\mathrm{m}$ run to $9.6 \mathrm{~K}$ in the 2.4-m run. Seasonal variations in $\triangle \mathrm{SST}$ are significantly correlated with those in $P_{\mathrm{CENT}}$ in all runs 
but the correlations are weaker than those between $P_{\mathrm{CENT}}$ and $\mathrm{AHT}_{\mathrm{EQ}}$ and decrease to an $R^{2}$ of 0.67 in the 50 -m run. The latter is a consequence of a phase lead of $\Delta \mathrm{SST}$ relative to $P_{\mathrm{CENT}}$ that increases with increasing mixed layer depth to 36 days for the $50-\mathrm{m}$ run. In contrast, $P_{\mathrm{CENT}}$ and $\mathrm{AHT}_{\mathrm{EQ}}$ are nearly antiphased in all runs with an average phase difference magnitude of 11 days. The regression coefficient between $P_{\mathrm{CENT}}$ and $\Delta \mathrm{SST}$ varies nonmonotonically with slab depth and reaches a maximum of $2.9^{\circ} \mathrm{K}^{-1}$ in the $24-\mathrm{m}$ run and a minimum of $1.4^{\circ} \mathrm{K}^{-1}$ in the $50-\mathrm{m}$ run with an ensemble average of $2.1^{\circ} \mathrm{K}^{-1}$.

\section{ITCZ shifts and cross-equatorial atmospheric heat transport change due to anthropogenic and paleoclimatic forcing}

The previous section demonstrated that there is a robust and consistent relationship between the $P_{\mathrm{CENT}}$ and $\mathrm{AHT}_{\mathrm{EQ}}$ and between $P_{\mathrm{CENT}}$ and $\Delta \mathrm{SST}$ over the seasonal cycle in both observations and coupled climate models. We now analyze the relationship between annual mean shifts in ITCZ location and change in $\mathrm{AHT}_{\mathrm{EQ}}$ and $\Delta \mathrm{SST}$ due to anthropogenic and paleoclimatic forcing. We argue that the same quantitative relationships found in the seasonal cycle also apply to the climate change problem across a myriad of different forcings.

\section{a. Model runs analyzed}

\section{1) CARBON DIOXIDE DOUBLING EXPERIMENTS}

We analyze the CMIP3 1\% $\mathrm{CO}_{2}$ increase to doubling experiments (Meehl et al. 2007). Each model is initialized from the equilibrated preindustrial (PI) or in some cases [CCSM, the Meteorological Research Institute (MRI) model, and ECHAM] the present-day (PD) simulations. Atmospheric carbon dioxide increases at a rate of $1 \%$ per year until it has doubled (at year 70) and is then held fixed for an additional 150 years of simulations. We calculate the climatology of each model over the last 20 years of simulations and then take differences relative to the climatology in the PI (or PD) run. We will refer to these runs as the $2 \mathrm{XCO}_{2}$ runs. Fifteen different models are analyzed.

\section{2) LAst Glacial MaXimum SimUlations}

We utilize model output from phase 2 of the Paleoclimate Modeling Intercomparison Project (PMIP2), an ensemble of state-of-the-art coupled (ocean-atmosphere-cryosphere) model simulations run under prescribed forcing and boundary condition scenarios that represent different paleoclimatic epochs. The Last Glacial Maximum (LGM) simulations are forced by insolation from 21000 years before present, with greenhouse gas and aerosol concentrations deduced from ice core data $\left(\mathrm{CO}_{2}\right.$ is set to $185 \mathrm{ppm}$ ), which amounts to a radiative forcing of approximately $-2.8 \mathrm{~W} \mathrm{~m}^{-2}$ (Braconnot et al. 2007a), coastlines consistent with a $120-\mathrm{m}$ decrease in sea level, and the prescribed land ice topography of Peltier (2004), which includes the expansive Laurentide ice sheet over North America. We use the LGM simulations with fixed vegetation (PMIP2 OA runs). All comparisons are made to the preindustrial simulations in the same model and resolution (many of which are lower resolution than the PI simulations analyzed in section $2 b$ ). Seven different model simulations are analyzed.

\section{3) 6000 YEARS BEFORE PRESENT SIMULATIONS}

The PMIP2 mid-Holocene runs are used (Braconnot et al. 2007a). We will refer to these experiments as the $6 \mathrm{Kyr}$ runs. Coastlines, vegetation, and ice sheets are identical to the PI simulations. $\mathrm{CO}_{2}$ and aerosols are also identical to the PI while there is a modest reduction in methane concentration (from 760 to $650 \mathrm{ppbv}$ ). Orbital parameters representative of 6000 years before the present are taken from Berger and Loutre (1991). Most significantly, orbital precession causes the seasonal cycle of insolation in the Northern Hemisphere to amplify, while the duration of summer is reduced; the seasonal amplitude of $\left\langle\mathrm{SW}_{\downarrow, \mathrm{TOA}}\right\rangle$ increases by $2.5 \%$ relative to the PI climate. Enhanced obliquity causes more highlatitude insolation in the annual mean. We note that the sum of all mid-Holocene forcing agents is symmetric about the equator in the annual average. Six different model simulations of $6 \mathrm{Kyr}$ are analyzed.

\section{b. Results}

We present the results across all three forcing experiments here, and then further analyze the $2 \mathrm{XCO}_{2}, \mathrm{LGM}$, and $6 \mathrm{Kyr}$ experiments in sections $3 b(1)-3 b(3)$. The change in annual mean $P_{\mathrm{CENT}}$ in the three forcing experiments is plotted against the change in annual mean $\mathrm{AHT}_{\mathrm{EQ}}$ and $\Delta \mathrm{SST}$ in the top and bottom panels of Fig. 10, respectively. In the $\mathrm{LGM}$ and $2 \mathrm{XCO}_{2}$ experiments the intermodel spread in both the change in $P_{\mathrm{CENT}}$ and $\mathrm{AHT}_{\mathrm{EQ}}$ is larger than the ensemble average change and so the sign of the change is ambiguous (cf. the solid red and blue squares with the spread in the red and blue crosses across both axes); the ensemble average change in $P_{\mathrm{CENT}}$ and $\mathrm{AHT}_{\mathrm{EQ}}$ is not significantly different from zero in the LGM and $2 \mathrm{XCO}_{2}$ runs. This result is surprising, especially in the LGM case, where one would expect that the large Laurentide ice sheet in the Northern Hemisphere would lead to a deficit of absorbed shortwave radiation (a positive change $\left\langle\mathrm{SW}_{\text {NET,TOA }}\right\rangle$ ) leading to a cooling in the Northern Hemisphere (relative to the Southern Hemisphere), a decrease in $\Delta$ SST, 

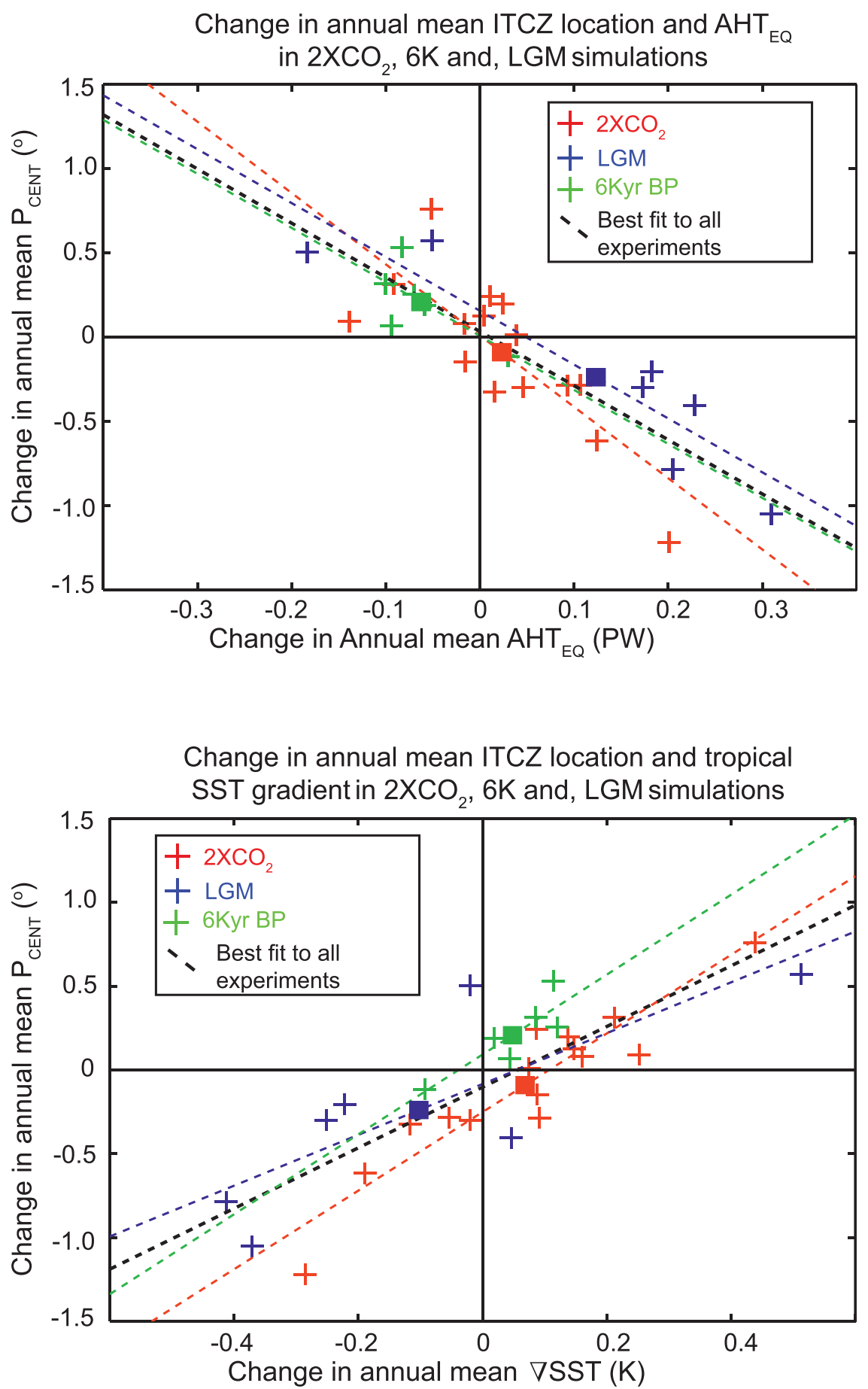

FIG. 10. (top) Change in annual mean precipitation centroid vs change in cross-equatorial heat transport in the atmosphere in the $2 \mathrm{XCO}_{2}$ simulations (each red cross is a different ensemble member), 6000 years before present simulations (green crosses), and Last Glacial Maximum simulation (blue crosses). The dashed red, green, and blue lines are the linear best fits in the $2 \mathrm{XCO}_{2}, 6 \mathrm{Kyr}$, and LGM runs, respectively. The dashed black line is the linear best fit to all experiments. The filled boxes are the ensemble mean of each simulation. (bottom) As at top, but for change in annual mean precipitation centroid $\left(P_{\mathrm{CENT}}\right)$ vs change in tropical SST gradient $(\Delta \mathrm{SST})$. 
a southward shift in $P_{\text {CENT }}$, and more northward $\mathrm{AHT}_{\mathrm{EQ}}$. This result suggests that intermodel differences in the spatial structure of climate feedbacks can play a bigger role in setting the interhemispheric contrast of the temperature and energetic response than does the interhemispheric contrast in climate forcing and boundary conditions themselves.

In contrast to the $\mathrm{LGM}$ and $2 \mathrm{XCO}_{2}$ experiments, in the $6 \mathrm{Kyr}$ simulations there is a significant $(99 \%$ confidence interval) ensemble average northward shift of $P_{\mathrm{CENT}}$ of $0.21^{\circ}$, a decrease (more southward) in $\mathrm{AHT}_{\mathrm{EQ}}$ of $-0.06 \mathrm{PW}$, and a $0.06 \mathrm{~K}$ increase in $\Delta$ SST (Table 3). Despite the lack of significance of the ensemble average changes in the $2 \mathrm{XCO}_{2}$ and LGM experiments, the ensemble average changes in $P_{\mathrm{CENT}}$ and $\mathrm{AHT}_{\mathrm{EQ}}$ are consistent with the relationship found in the seasonal cycle in section 2; the ensemble average southward shift of the ITCZ in the LGM is accompanied by a more northward $\mathrm{AHT}_{\mathrm{EQ}}$ while the ensemble average northward ITCZ shift in the $6 \mathrm{Kyr}$ experiment is accompanied by more southward $\mathrm{AHT}_{\mathrm{EQ}}$ (and the ensemble average $2 \mathrm{XCO}_{2}$ change is more neutral) with a quantitative relationship of approximately $-3^{\circ} \mathrm{PW}^{-1}$. In contrast, the robust relationship between $P_{\mathrm{CENT}}$ and $\Delta$ SST found in the seasonal cycle does not predict the ensemble average ITCZ shift in the $2 \mathrm{XCO}_{2}$ runs. Here the increase in $\Delta$ SST is accompanied by a southward shift in $P_{\text {CENT }}$.

In each experiment, the change in annual mean $P_{\mathrm{CENT}}$ and $\mathrm{AHT}_{\mathrm{EQ}}$ changes are significantly negatively correlated among the ensemble members with an average correlation coefficient of -0.81 and a correlation coefficient of -0.85 when considering all experiments collectively. The regression coefficient between $P_{\text {CENT }}$ and $\mathrm{AHT}_{\mathrm{EQ}}$ ranges from $-4.2^{\circ} \mathrm{PW}^{-1}$ in the $2 \mathrm{XCO}_{2}$ ensemble to $-3.2^{\circ} \mathrm{PW}^{-1}$ in the LGM and $6 \mathrm{Kyr}$ ensembles (Table 3 ) and the regression coefficient of all simulations considered simultaneously is $-3.2^{\circ} \mathrm{PW}^{-1}$. These relationships are in good agreement with the seasonal slope between $P_{\mathrm{CENT}}$ and $\mathrm{AHT}_{\mathrm{EQ}}$ of $-2.7^{\circ} \mathrm{PW}^{-1}$ found in the observations. These results collectively suggest that the relationship between $P_{\mathrm{CENT}}$ and $\mathrm{AHT}_{\mathrm{EQ}}$ is robust across time scales (seasonal vs annual mean) and across different climate states. We return to this point in the discussion section.

The intermodel spread in annual mean $P_{\text {CENT }}$ and $\Delta$ SST changes are significantly positively correlated in all three perturbation experiments with an average correlation coefficient of 0.86 and a slope that ranges from $+1.5^{\circ} \mathrm{K}^{-1}$ in the $\mathrm{LGM}$ simulations to $+2.4^{\circ} \mathrm{K}^{-1}$ in the $6 \mathrm{Kyr}$ experiments (Table 3). These slopes are significantly shallower but of similar magnitude to that found in the seasonal cycle in the observations $\left(+3.3^{\circ} \mathrm{K}^{-1}\right)$.
TABLE 3. Ensemble average, spread $(1 \sigma)$, and regression coefficients for $P_{\mathrm{CENT}}, \mathrm{AHT}_{\mathrm{EQ}}$, and $\Delta \mathrm{SST}$ in the $2 \mathrm{XCO}_{2}, \mathrm{LGM}$, and $6 \mathrm{Kyr}$ experiment.

\begin{tabular}{|c|c|c|c|}
\hline & $2 \mathrm{XCO}_{2}$ & LGM & $6 \mathrm{Kyr}$ \\
\hline $\begin{array}{l}\text { Ensemble avg change } \\
\text { in } P_{\text {CENT }}\left({ }^{\circ}\right)\end{array}$ & -0.09 & -0.24 & +0.21 \\
\hline $\begin{array}{l}\text { Ensemble spread }(1 \sigma) \text { of } \\
\text { change in } P_{\text {CENT }}\left({ }^{\circ}\right)\end{array}$ & 0.46 & 0.61 & 0.22 \\
\hline $\begin{array}{l}\text { Ensemble avg change } \\
\text { in } \mathrm{AHT}_{\mathrm{EQ}}(\mathrm{PW})\end{array}$ & +0.02 & +0.12 & -0.06 \\
\hline $\begin{array}{l}\text { Ensemble spread }(1 \sigma) \text { of } \\
\text { change in } \mathrm{AHT}_{\mathrm{EQ}}(\mathrm{PW})\end{array}$ & 0.09 & 0.17 & 0.05 \\
\hline $\begin{array}{l}\text { Ensemble avg change } \\
\text { in } \Delta \mathrm{SST}(\mathrm{K})\end{array}$ & +0.06 & -0.10 & +0.06 \\
\hline $\begin{array}{l}\text { Ensemble spread }(1 \sigma) \text { of } \\
\text { change in } \Delta \text { SST }(\mathrm{PW})\end{array}$ & 0.18 & 0.32 & 0.07 \\
\hline $\begin{array}{l}\text { Regression coef between } \\
\text { change in } P_{\mathrm{CENT}} \text { and } \\
\mathrm{AHT}_{\mathrm{EQ}}\left({ }^{\circ} \mathrm{PW}^{-1}\right)\end{array}$ & -4.2 & -3.2 & -3.2 \\
\hline $\begin{array}{l}\text { Regression coef between } \\
\text { change in } P_{\mathrm{CENT}} \text { and } \\
\Delta \mathrm{SST}\left({ }^{\circ} \mathrm{K}^{-1}\right)\end{array}$ & +2.3 & +1.5 & +2.4 \\
\hline
\end{tabular}

\section{1) $2 \mathrm{XCO}_{2}$ EXPERIMENTS}

The ITCZ response to $\mathrm{CO}_{2}$ doubling in the CMIP3 slab ocean simulations was analyzed thoroughly by Frierson and Hwang (2012), who concluded that there are large intermodel differences in the annual mean ITCZ shift due to differences in the $\mathrm{AHT}_{\mathrm{EQ}}$ change that primary reflect intermodel differences in extratropical feedbacks. We find a similar relationship between $P_{\mathrm{CENT}}$ and $\mathrm{AHT}_{\mathrm{EQ}}$ in the coupled $1 \% \mathrm{CO}_{2}$ increase runs. The ensemble average $0.02 \mathrm{PW}$ increase $\mathrm{AHT}_{\mathrm{EQ}}$ in the $2 \mathrm{XCO}_{2}$ simulations analyzed in this study is decomposed into a nearly compensating $0.22 \mathrm{PW}$ increase in $\left\langle\mathrm{SW}_{\text {NET,TOA }}\right\rangle$ [associated with increased cloudiness in the Northern Hemisphere midlatitudes as assessed by the method of Donohoe and Battisti (2011)] and a $0.29 \mathrm{PW}$ increase in $\langle\mathrm{OLR}\rangle$ (associated primarily with the Planck feedback and larger temperature increases in the Northern Hemisphere as compared to those in the Southern Hemisphere). Additionally, there is a $0.09 \mathrm{PW}$ decrease in $\langle\mathrm{OHT}+S\rangle$, which implies either more southward ocean heat transport or more transient heat storage in the Northern Hemisphere as compared to the Southern Hemisphere. We emphasize that the ensemble average change in the hemispheric contrast of the energy budget due to $\mathrm{CO}_{2}$ doubling is small compared to the intermodel spread as pointed out by Zelinka and Hartmann (2012) and Frierson and Hwang (2012). Furthermore the ITCZ shift due to anthropogenic climate forcing varies in sign between models and depends critically on extratropical climate feedbacks. 


\section{2) LGM EXPERIMENTS}

The most pronounced change in the interhemispheric energy budget in the LGM is the presence of the Laurentide ice sheet in the Northern Hemisphere; the cryosphere expanded drastically in the Northern Hemisphere and only modestly in the Southern Hemisphere during the LGM. The ensemble average spatially and solar weighted surface albedo of the Northern Hemisphere increased by 0.029 relative to that in the Southern Hemisphere (with an ensemble standard deviation of 0.018 due to differences in the albedo of the Laurentide ice sheet), which translates to an increase in $\left\langle\mathrm{SW}_{\mathrm{NET}, \mathrm{TOA}}\right\rangle$ of $+1.30 \mathrm{PW}$ if the same surface albedo change was found in the planetary albedo. However, the shortwave atmospheric opacity limits the surface albedo's impact on the TOA radiative budget while decreased cloudiness over the ice sheet compensates for the increased surface reflection and the ensemble average change in $\left\langle\mathrm{SW}_{\mathrm{NET}, \mathrm{TOA}}\right\rangle$ is $+0.43 \mathrm{PW}$ (and ranges from +0.03 to $+0.84 \mathrm{PW}$ in the ensemble members). Using the method of Donohoe and Battisti (2011) to partition the planetary albedo into contributions from surface albedo and cloud reflection, we find that the ensemble average change in $\left\langle\mathrm{SW}_{\mathrm{NET}, \mathrm{TOA}}\right\rangle$ is due to a $+0.60 \mathrm{PW}$ contribution from changes in surface albedo and a $-0.17 \mathrm{PW}$ contribution from changes in atmospheric reflection (fewer clouds over the ice sheet).

The deficit of absorbed shortwave radiation in the Northern Hemisphere (a positive change in $\left\langle\mathrm{SW}_{\text {NET,TOA }}\right\rangle$ ) leads to a cooling of the Northern Hemisphere (relative to the Southern Hemisphere) and must either be balanced radiatively by decreased OLR $(\langle\mathrm{OLR}\rangle)$, or dynamically by increasing either atmospheric $\left(\mathrm{AHT}_{\mathrm{EQ}}\right)$ or oceanic heat transport and storage $(\langle\mathrm{OHT}+S\rangle)$. The ensemble average $0.43 \mathrm{PW}$ increase $\left\langle\mathrm{SW}_{\text {NET,TOA }}\right\rangle$ (i.e., less shortwave radiation absorbed in the Northern Hemisphere) is balanced primarily by a $0.32 \mathrm{PW}$ increase in $\langle$ OLR $\rangle$ (i.e., a decrease in OLR in the Northern Hemisphere), secondarily by a 0.12 increase in $\mathrm{AHT}_{\mathrm{EQ}}$ and is slightly opposed by a $0.01 \mathrm{PW}$ decrease in $\langle\mathrm{OHT}+S\rangle$. Intermodel differences in $\left\langle\mathrm{SW}_{\mathrm{NET}, \mathrm{TOA}}\right\rangle$ are well correlated with both intermodel differences in $\langle\mathrm{OLR}\rangle$ and $\mathrm{AHT}_{\mathrm{EQ}}$ (with correlations coefficients of 0.88 and 0.87 , respectively) with nearly equal magnitude regression coefficients. These results suggest that the deficit in absorbed shortwave radiation in the Northern Hemisphere induced by the Laurentide ice sheet is primarily balanced radiatively (by OLR anomalies) and only secondarily by dynamics (atmospheric heat transport changes), with less than half of the shortwave anomaly being realized in the atmospheric heat transport change. In summary, the rather large interhemispheric contrast in energetics induced by the Laurentide ice sheet's albedo (1.30 PW) is largely damped by 1 ) the factor of approximately 2.5 attenuation of the surface albedo's impact on the TOA energy budget by the atmospheric shortwave opacity, 2) compensating decreases in cloudiness over the Laurentide ice sheet, and 3) radiative compensation via the Planck feedback. As a result, approximately $10 \%(0.12 \mathrm{PW})$ of the energetics implied by the surface albedo changes are realized in crossequatorial atmospheric heat transport, resulting in a very modest ensemble average shift in the ITCZ location.

Braconnot et al. (2007b) previously demonstrated the surprising result that, in PMIP2 LGM simulations, the meridional shift of the ITCZ during the boreal summer differs in sign between the ensemble members. We find here that indeed, and contrary to expectations, two models shift the annual mean ITCZ toward the Northern Hemisphere. We note that, in both cases, these changes are expected given the change in $\mathrm{AHT}_{\mathrm{EQ}}$ and the relationship between $P_{\mathrm{CENT}}$ and $\mathrm{AHT}_{\mathrm{EQ}}$. We now discuss the cause of the negative (more southward) change in $\mathrm{AHT}_{\mathrm{EQ}}$ in these two models. In ECHAM5, $\left\langle\mathrm{SW}_{\mathrm{NET}, \mathrm{TOA}}\right\rangle$ increases by $0.24 \mathrm{PW}$, primarily due to the surface albedo change, and $\langle\mathrm{OLR}\rangle$ increases by $0.46 \mathrm{PW}$, primarily due to the Planck feedback and more cooling in the Northern Hemisphere as compared to the Southern Hemisphere. Because the $\langle\mathrm{OLR}\rangle$ change is larger in magnitude than the $\left\langle\mathrm{SW}_{\mathrm{NET}, \mathrm{TOA}}\right\rangle$ change, the ice sheet actually introduces a net source of energy to the atmosphere in the Northern Hemisphere due to radiative overcompensation and $\mathrm{AHT}_{\mathrm{EQ}}$ moves energy away from the energy source in the Northern Hemisphere, resulting in a northward ITCZ shift. In FGOALS, the total heat transport across the equator is nearly unchanged $(-0.05 \mathrm{PW})$ due to a large radiative compensation with the change in $\left\langle\mathrm{SW}_{\text {NET,TOA }}\right\rangle$ being nearly, but not completely balanced by $\langle\mathrm{OLR}\rangle$. Concurrently, $\langle\mathrm{OHT}+S\rangle$ increases by $0.10 \mathrm{PW}$ either due to more northward ocean heat transport or transient energy storage in the Southern Ocean. As a consequence, $\mathrm{AHT}_{\mathrm{EQ}}$ decreases by $0.05 \mathrm{PW}$, largely reflecting compensation between oceanic and atmospheric heat transport, and the ITCZ shifts northward.

\section{3) 6KYR EXPERIMENTS}

The robust annual mean northward ITCZ shift and more southward $\mathrm{AHT}_{\mathrm{EQ}}$ in the $6 \mathrm{Kyr}$ runs is surprising given that there is no interhemispheric contrast of forcing in the annual mean and implies that nonlinearities in the seasonal response to forcing play a vital role in setting the ITCZ location. In the ensemble average, the changes in net radiation at the TOA have a minimal impact on $\mathrm{AHT}_{\mathrm{EQ}}$ as the $0.06 \mathrm{PW}$ increase in $\left\langle\mathrm{SW}_{\mathrm{NET}, \mathrm{TOA}}\right\rangle$ (associated with reduced cloudiness in the Northern 
Hemisphere midlatitudes) is nearly balanced by a $0.05 \mathrm{PW}$ increase in $\langle\mathrm{OLR}\rangle$ (associated with warming of the northern subtropics). Ultimately, the ensemble average $0.06 \mathrm{PW}$ decrease (more southward) in $\mathrm{AHT}_{\mathrm{EQ}}$ is a consequence of a 0.07 increase in $\langle\mathrm{OHT}+S\rangle$. Our analysis techniques cannot distinguish between a change in crossequatorial ocean heat transport and a hemispheric asymmetry of transient ocean storage. The annual mean shift in the $6 \mathrm{Kyr}$ runs reflects the ITCZ moving farther northward during the boreal summer while the ITCZ migration into the Southern Hemisphere during the austral summer is nearly unchanged relative to that in the PI simulations, as discussed further in our concluding remarks.

\section{Summary and discussion}

The seasonal cycle of the location of the ITCZ $\left(P_{\mathrm{CENT}}\right)$ is highly anticorrelated with the atmospheric heat transport at the equator $\left(\mathrm{AHT}_{\mathrm{EQ}}\right)$ and highly correlated with the interhemispheric contrast of tropical sea surface temperatures ( $\triangle \mathrm{SST})$ in both the observations $\left(R^{2}=0.99\right.$ and 0.94 respectively) and coupled climate models $\left(R^{2}=0.80\right.$ and 0.94 respectively). We argue that the relationship between $P_{\mathrm{CENT}}$ and $\mathrm{AHT}_{\mathrm{EQ}}$ is a consequence of their mutual association with the meridional migration of the Hadley cell. The regression coefficient between $P_{\mathrm{CENT}}$ and $\mathrm{AHT}_{\mathrm{EO}}$ over the seasonal cycle is $-2.7^{\circ} \mathrm{PW}^{-1}$ in the observations and agrees well with the CMIP3 ensemble average of $-2.4^{\circ} \mathrm{PW}^{-1}$. Similarly, the regression coefficient between $P_{\mathrm{CENT}}$ and $\Delta$ SST over the seasonal cycle is $+3.3^{\circ} \mathrm{K}^{-1}$ in the observations and agrees well with the CMIP3 ensemble average of $+3.7^{\circ} \mathrm{PW}^{-1}$.

The annual mean shift in ITCZ $\left(P_{\mathrm{CENT}}\right)$ across a myriad of climate forcing experiments $\left(2 \mathrm{XCO}_{2}, \mathrm{LGM}\right.$, and mid-Holocene) in coupled climate models is well correlated with the change in $\mathrm{AHT}_{\mathrm{EQ}}$ with a regression coefficient of $-3.2^{\circ} \mathrm{PW}^{-1}$, in excellent agreement with that found over the seasonal cycle. This result suggests that the same physics that control the seasonal cycle of $\mathrm{AHT}_{\mathrm{EQ}}$ and $P_{\mathrm{CENT}}$, via their mutual connection to the Hadley cell, also control changes in the annual mean.

The seasonal relationship between $P_{\text {CENT }}$ and $\mathrm{AHT}_{\mathrm{EQ}}$ was found to depend on how far off the equator the ITCZ moves in a series of aquaplanet simulations with varying mixed layer depth. We argue that the asymmetry between the winter and summer Hadley cells is critical to this result due to two processes: 1) $\mathrm{AHT}_{\mathrm{EQ}}$ changes more than would be expected from simply translating the annual mean Hadley cell off the equator due to the intensification of the streamfunction in the winter cell as the Hadley cell moves off the equator, and 2) the ITCZ remains equatorward of the zero streamfunction because the maximum meridional divergence of the streamfunction and upward motion gets pushed into the winter cell due to the asymmetry between the winter and summer Hadley cells. As a consequence, the $\mathrm{AHT}_{\mathrm{EQ}}$ change required per degree shift in the ITCZ increases as the ITCZ moves farther off the equator. We note that, in the annual average, the ITCZ is relatively close to the equator and the two branches of the Hadley cell are nearly symmetric as compared to the seasonal extremes. This might lead one to believe that the $\mathrm{AHT}_{\mathrm{EQ}}$ change required to move the ITCZ $1^{\circ}$ would be comparable to that expected from simply translating the Hadley cell meridionally without the concurrent intensification of the winter cell (on the order of $0.1 \mathrm{PW}$; see red asterisks in Fig. 5) and less than that found over the seasonal cycle (on the order of $0.3 \mathrm{PW}$; see upper panel of Fig. 3). Yet, we concluded above that the relationship between $P_{\mathrm{CENT}}$ and $\mathrm{AHT}_{\mathrm{EQ}}$ over the observed seasonal cycle is statistically indistinguishable from the relationship found for the annual mean changes across the ensemble of climate change perturbation experiments. We argue below that the seasonal relationships between $P_{\text {CENT }}$ and $\mathrm{AHT}_{\mathrm{EQ}}$ is dictated by the seasonal cycle because the annual average is seldom realized and is better thought of as the average of the seasonal extremes (and the amount of time spent in the extreme) as illustrated in Fig. 7.

The top panel of Fig. 11 shows smoothed histograms (Eilers and Goeman 2004) of monthly mean $P_{\text {CENT }}$ and $\mathrm{AHT}_{\mathrm{EO}}$ for 200 years of the PI simulation in the IPSL model. The annual mean (black cross) is seldom realized and the system rapidly migrates between seasonal extremes of $P_{\text {CENT }}$ in the Northern Hemisphere and southward $\mathrm{AHT}_{\mathrm{EQ}}$ in the boreal summer and $P_{\mathrm{CENT}}$ in the Southern Hemisphere and northward $\mathrm{AHT}_{\mathrm{EQ}}$ in the austral summer. The linear best fit (dashed black line) connects the seasonal extremes with a slope equal to the regression coefficient between $P_{\mathrm{CENT}}$ and $\mathrm{AHT}_{\mathrm{EQ}}$ and nearly passes through the origin. By statistical construction, the annual mean lies on the linear best fit line. In short, the annual mean reflects the average of the two seasonal extremes. ${ }^{4}$

The smoothed histogram and linear best fit of $P_{\text {CENT }}$ and $\mathrm{AHT}_{\mathrm{EQ}}$ for the IPSL $2 \mathrm{XCO}_{2}$ simulation are very similar to their PI counterparts (middle panel of Fig. 11). However, during both seasonal extremes, $P_{\mathrm{CENT}}$ has

\footnotetext{
${ }^{4}$ We note that, in this particular case, the time spent in the boreal and austral summer extremes is approximately equal (the lobes of the smoothed histogram are comparable in magnitude) and the annual mean falls nearly equidistant from the extremes. If more time was spent in either of the seasonal extremes, the lobes would have different magnitudes and the annual mean would be shifted toward the more populated lobe.
} 
shifted southward and there is more northward $\mathrm{AHT}_{\mathrm{EQ}}$. As a consequence, the annual average $P_{\mathrm{CENT}}$ and $\mathrm{AHT}_{\mathrm{EQ}}$ have also shifted in the same sense as the seasonal extremes. The key point is that, provided that the seasonal relationship between $P_{\mathrm{CENT}}$ and $\mathrm{AHT}_{\mathrm{EQ}}$ is consistent between climate states, the annual mean shifts along the seasonal linear best fit; the relationship between annual mean shift in $P_{\mathrm{CENT}}$ and $\mathrm{AHT}_{\mathrm{EQ}}$ will be the same as the relationship between $P_{\mathrm{CENT}}$ and $\mathrm{AHT}_{\mathrm{EQ}}$ found over the seasonal cycle. We extend this analysis to the LGM and $6 \mathrm{Kyr}$ runs alongside the PI and $2 \mathrm{XCO}_{2}$ in the bottom panel of Fig. 11 where a single smoothed histogram contour $\left[2.5 \%\left({ }^{\circ} \mathrm{PW}\right)^{-1}\right]$ is shown for visual purposes. There we see that while the shift from the PI to $2 \mathrm{XCO}_{2}$ is apparent in both seasons, in the $6 \mathrm{Kyr}$ run the boreal summer extreme shifts farther away from the origin (along the seasonal slope) while the austral summer statistics are relatively unchanged. In contrast, in the LGM the ITCZ and $\mathrm{AHT}_{\mathrm{EQ}}$ are relatively unchanged during the boreal summer while, in the austral summer, the ITCZ shifts more southward and the $\mathrm{AHT}_{\mathrm{EQ}}$ becomes more northward. In all cases, the asymmetric shifting of the seasonal extremes result in a shift of the annual mean and, most importantly, the annual mean shifts along the seasonal slope between $P_{\mathrm{CENT}}$ and $\mathrm{AHT}_{\mathrm{EQ}}$.

Our framework suggest that perturbations to the interhemispheric asymmetry of atmospheric energy budget [Eq. (4)] at all latitudes and from all sources (e.g., ocean heat transport anomalies, surface heat flux anomalies, and radiative perturbations) have an equal impact on $\mathrm{AHT}_{\mathrm{EQ}}$ and on the ITCZ location via the connection between $P_{\mathrm{CENT}}$ and $\mathrm{AHT}_{\mathrm{EQ}}$. Similar ideas have been expressed by Chiang and Bitz (2005), Kang et al. (2008), Frierson and Hwang (2012), and Yoshimori and Broccoli (2008), among others. In contrast, there is an abundance of literature on the role of tropical processes in setting the ITCZ location including the coastal geometry (Philander et al. 1996), the roles of the Andes is shaping the spatial structure of SST (Takahashi and Battisti 2007), and the role of the tropical oceanic circulation (Clement and Seager 1999), among others. We note that, while our results speculate that extratropical energy inputs play a vital role in setting and shifting the ITCZ location, we have not demonstrated causality. The interhemispheric energy budget must come into balance with $\mathrm{AHT}_{\mathrm{EQ}}$ changes that accompany ITCZ shifts and the resulting radiative and surface heat flux anomalies could be a manifestation of changes in the tropics.

Our results have implications for ITCZ location in paleoclimate states, some of which have already been discussed in the context of the PMIP2 models (section 3). In particular, paleoclimate records have been used to deduce ITCZ shifts and, in some cases, have been used
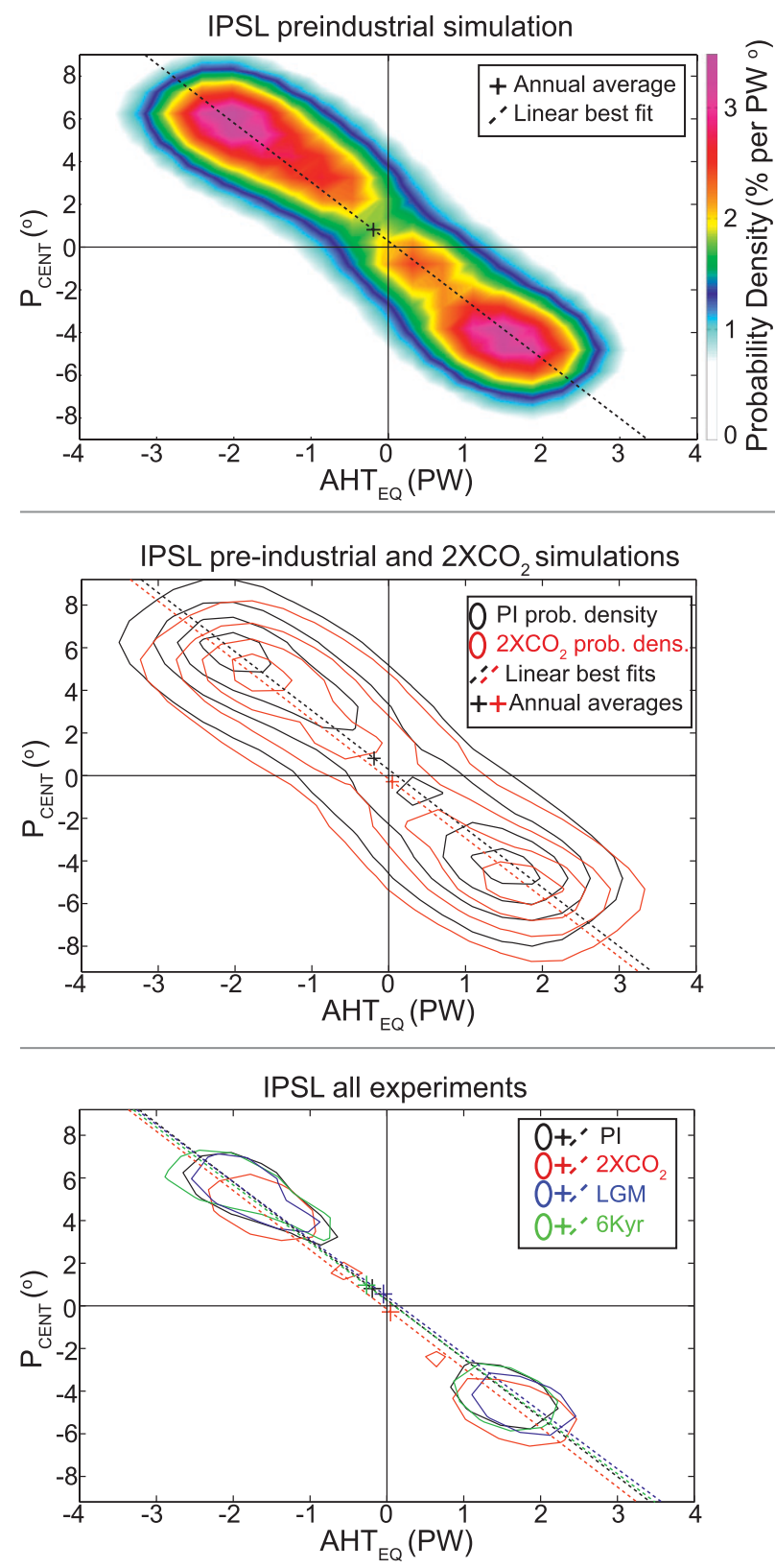

FIG. 11. (top) Smoothed histogram (colors) in the $\mathrm{AHT}_{\mathrm{EQ}^{-}}$ $P_{\text {CENT }}$ plane taken from a 200 -yr-long PI simulation in the L'Institut Pierre-Simon Laplace (IPSL) model. The dashed line is the linear best fit to the monthly data for all years of the simulation and the cross is the annual average. (middle) As at top, but the probability density function is contoured [contour interval of $0.75 \%\left({ }^{\circ} \mathrm{PW}\right)^{-1}$ ] with black contours showing the PI values and red values showing the $2 \mathrm{XCO}_{2}$ values. The red and black crosses and dashed lines represent the annual average and linear best fits in the $2 \mathrm{XCO}_{2}$ and PI simulations respectively. (bottom) As in the middle panel except only the $2.5 \%\left({ }^{\circ} \mathrm{PW}\right)^{-1}$ contour is shown. The PI simulation is shown in black, $2 \mathrm{XCO}_{2}$ in red, LGM in blue, and the $6 \mathrm{Kyr}$ simulation in green. 
to quantify bounds on meridional position of the ITCZ (i.e., Sachs et al. 2009) over Earth's history. The quantitative scaling of the relationship between ITCZ position and $\mathrm{AHT}_{\mathrm{EQ}}$ found in this study allows one to infer the change in cross-equatorial atmospheric heat transport implied by the paleoclimate reconstructions of ITCZ location, and ultimately relate these quantities back to the hemispheric-scale energy budget (Fig. 2) of the climate system. For example, the southward ITCZ shift on the order of $5^{\circ}$ during the Little Ice Age suggested by Sachs et al. (2009) implies an $\mathrm{AHT}_{\mathrm{EQ}}$ change of approximately 1.7 PW; presently, there is no known climate forcing or feedback during that time period that could account for such a large energy perturbation at the hemispheric scale. Similarly, the same ITCZ shift would be associated with a $\Delta$ SST change within the range of 1.5-3.7 $\mathrm{K}$ (using the range of regression coefficients between $P_{\mathrm{CENT}}$ and $\Delta \mathrm{SST}$ found in this study) that ought to be readily seen in proxy SST reconstructions. We view the relationship between $P_{\mathrm{CENT}}$ and $\mathrm{AHT}_{\mathrm{EQ}}$ to be fundamental to the system because of the mutual dependence of the tropical rainfall and the atmospheric heat transport on the Hadley cell; we expect this relationship to hold from one climate state to the next because the seasonal anomalies are large compared to the climate perturbations and thus the seasonal cycle captures the system behavior to a fairly wide range of climate forcings. In contrast, we view the relationship between ITCZ location and $\triangle$ SST as empirical and potentially variant to the climates. However, $\Delta$ SST may be easier to constrain from paleo data and, thus, its relationship to the ITCZ location could help to place paleo observations into the framework presented in this manuscript.

Our analysis has focused on the zonal mean tropical precipitation and atmospheric heat transport. Clearly, paleoclimate records are indicative of more localized climate changes; the ITCZ shifts noted by Sachs et al. (2009) are derived from data along a latitudinal transect over a given longitudinal band in the Pacific. It remains to be seen if the diagnostics used in this study are applicable to more localized records as would be the case if ITCZ movements were zonally homogeneous, as suggested by Frierson and Hwang (2012). In future work, we hope to assess if the relationships among ITCZ location, $\mathrm{AHT}_{\mathrm{EQ}}$, and $\Delta$ SST found in this study can be applied to specific paleoclimate reconstructions in order to deduce past changes in the large-scale atmospheric circulation and the energetic processes responsible for those changes.

Acknowledgments. AD was supported by the NOAA Global Change Postdoctoral Fellowship. We thank Dargan Frierson for providing the GFDL aquaplanet simulations. We acknowledge the modeling groups, the Program for Climate Model Diagnosis and Intercomparison (PCMDI), and the WCRP's Working Group on Coupled Modelling (WGCM) for their roles in making available the WCRP CMIP3 multimodel dataset. Support of this dataset is provided by the Office of Science, U.S. Department of Energy. We also thank three anonymous reviewers and Editor John Chiang for insightful comments and edits.

\section{REFERENCES}

Berger, A., and M. Loutre, 1991: Insolation values for the climate of the last 10 million years. Quat. Sci. Rev., 10, 297-317.

Braconnot, P., and Coauthors, 2007a: Results of PMIP2 coupled simulations of the mid-Holocene and Last Glacial MaximumPart 1: Experiments and large-scale features. Climate Past, 3, 261-277.

- and Coauthors, 2007b: Results of PMIP2 coupled simulations of the mid-Holocene and Last Glacial Maximum-Part 2: Feedbacks with emphasis on the location of the ITCZ and mid- and high latitudes heat budget. Climate Past, 3, 279-296.

Chiang, J., and C. Bitz, 2005: The influence of high latitude ice on the position of the marine intertropical convergence zone. Climate Dyn., 25, 477-496, doi:10.1007/s00382-005-0040-5.

Clement, A., and R. Seager, 1999: Climate and the tropical oceans. J. Climate, 12, 3383-3401.

Czaja, A., and J. Marshall, 2006: The partitioning of poleward heat transport between the atmosphere and the ocean. J. Atmos. Sci., 63, 1498-1511.

Delworth, T. L., and Coauthors, 2006: GFDL'S CM2 global coupled climate models. Part I: Formulation and simulation characteristics. J. Climate, 19, 643-674.

Dima, I., and J. Wallace, 2003: On the seasonality of the Hadley cell. J. Climate, 60, 1522-1527.

Donohoe, A., 2011: Radiative and dynamic controls of global scale energy fluxes. Ph.D. thesis, University of Washington, $137 \mathrm{pp}$.

, and D. Battisti, 2011: Atmospheric and surface contributions to planetary albedo. J. Climate, 24, 4402-4418.

— , and —, 2012: What determines meridional heat transport in climate models? J. Climate, 25, 3832-3850.

— and _ 2013: The seasonal cycle of atmospheric heating and temperature. J. Climate, in press.

Eilers, P., and J. Goeman, 2004: Enhancing scatterplots with smoothed densities. Bioinformatics, 20, 623-628.

Fasullo, J. T., and K. E. Trenberth, 2008: The annual cycle of the energy budget. Part II: Meridional structures and poleward transports. J. Climate, 21, 2313-2325.

Frierson, D. M. W., and Y.-T. Hwang, 2012: Extratropical influence on ITCZ shifts in slab ocean simulations of global warming. J. Climate, 25, 720-733.

Hadley, G., 1735: Concerning the cause of the general trade-winds. Philos. Trans. Roy. Soc. London, 29, 58-62.

Haug, G., K. Hughen, D. Sigman, L. Peterson, and U. Röhl, 2001: Southward migration of the intertropical convergence zone through the Holocene. Science, 293, 1304-1308.

Held, I., 2001: The partitioning of the poleward energy transport between the tropical ocean and atmosphere. Science, 58, 943-948.

Kalnay, E., and Coauthors, 1996: The NCEP/NCAR 40-Year Reanalysis Project. Bull. Amer. Meteor. Soc., 77, 437-471.

Kang, S., I. Held, D. Frierson, and M. Zhao, 2008: The response of the ITCZ to extratropical thermal forcing: Idealized slabocean experiments with a GCM. J. Climate, 21, 3521-3532. 
Lin, S. J., 2004: A “vertically Lagrangian” finite-volume dynamical core for global models. Mon. Wea. Rev., 132, 2293-2307.

Lindzen, R., and A. Hou, 1988: Hadley circulations of zonally averaged heating centered off the equator. J. Atmos. Sci., 45, 2416-2427.

Meehl, G. A., C. Covey, T. Delworth, M. Latif, B. McAvaney, J. F. B. Mitchell, R. J. Stouffer, and K. E. Taylor, 2007: The WCRP CMIP3 multi-model dataset: A new era in climate change research. Bull. Amer. Meteor. Soc., 88, 1383-1394.

Pahnke, K., J. P. Sachs, L. Keigwin, A. Timmerman, and S. P. Xie, 2007: Eastern tropical Pacific hydrologic changes during the past 27,000 years from D/H ratios in alkenones. Paleoceanography, 22, PA4214, doi:10.1029/2007PA001468.

Peltier, W., 2004: Global glacial isostasy and the surface of the ice-age earth: The ICE-5G (VM2) model and GRACE. Annu. Rev. Earth Planet. Sci., 22, 111-149.

Peterson, L., G. Haug, K. Hughen, and U. Röhl, 2000: Rapid changes in the hydrologic cycle of the tropical Atlantic during the last glacial. Science, 290, 1947-1951.

Philander, S. G., D. Gu, D. Halpern, G. Lambert, N. Lau, T. Li, and R. Pacanowski, 1996: Why the ITCZ is mostly north of the equator. J. Climate, 9, 2958-2972.

Reynolds, R., and T. Smith, 1994: Improved global sea surface temperature analyses. J. Climate, 7, 929-948.

Sachs, J., D. Sachse, R. Smittenberg, Z. Zhang, D. Battisti, and S. Golubic, 2009: Southward movement of the Pacific intertropical convergence zone AD 1400-1850. Nat. Geosci., 2, $519-525$.

Smith, T., R. Reynolds, T. Peterson, and J. Lawrimore, 2008: Improvements to NOAA's historical merged land-ocean surface temperature analysis (1880-2006). J. Climate, 21, 2283-2296.
Takahashi, K., and D. Battisti, 2007: Processes controlling the mean tropical Pacific precipitation pattern. Part I: The Andes and the eastern Pacific ITCZ. J. Climate, 20, 3434-3451.

Trenberth, K. E., 1997: Using atmospheric budgets as a constraint on surface fluxes. J. Climate, 10, 2796-2809.

_ and ocean heat transports. J. Climate, 14, 3433-3443.

Waliser, D., and C. Gautier, 1993: A satellite-derived climatology of the ITCZ. J. Climate, 6, 2162-2174.

Wang, Y., H. Cheng, R. L. Edwards, Z. An, J. Wu, C.-C. Shen, and J. Dorale, 2001: A high-resolution absolute-dated late Pleistocene monsoon record from Hulu Cave, China. Science, 294, 2345-2348.

Wielicki, B., B. Barkstrom, E. Harrison, R. Lee, G. Smith, and J. Cooper, 1996: Clouds and the Earth's Radiant Energy System (CERES): An earth observing system experiment. Bull. Amer. Meteor. Soc., 77, 853-868.

Xian, P., and R. Miller, 2008: Abrupt seasonal migration of the ITCZ into the summer hemisphere. J. Atmos. Sci., 65, 1878-1895.

Xie, P., and P. Arkin, 1996: Analyses of global monthly precipitation using gauge observations, satellite estimates, and numerical model predictions. J. Climate, 9, 840-858.

Yoshimori, M., and A. J. Broccoli, 2008: Equilibrium response of an atmosphere mixed layer ocean model to different radiative forcing agents: Global and zonal mean response. J. Climate, 21, 4399-4423.

— and - , 2009: On the link between Hadley circulation changes and radiative feedback processes. Geophys. Res. Lett., 36, L20703, doi:10.1029/2009GL040488.

Zelinka, M., and D. Hartmann, 2012: Climate feedbacks and their implications for poleward energy flux changes in a warming climate. J. Climate, 25, 608-624. 